Tymofii Tereshchenko , Natasa Nord

Norwegian University of Science and Technology (NTNU)

Department of Energy and Process Engineering

Kolbjørn Hejes vei 1d

NO-7491 Trondheim

Norway

*Corresponding author. Mob: +4792553322

E-mail: tymofii.tereshchenko@ntnu.no

\title{
Energy planning of district heating for future building stock based on renewable energies and increasing supply flexibility
}

\section{Nomenclature:}

$\begin{array}{ll}C(E U R) & - \text { total annual cost } \\ c(E U R / k W) & - \text { specific total cost per capacity unit } \\ \tau(\text { hours }) & - \text { operation time } \\ P(M W) & - \text { anstalled heat power capacity for each plant } \\ Q(M W h) & - \text { break-even operation time for two energy units } \\ \tau_{n, m}(\text { hours } / \text { year }) & \end{array}$




$\begin{array}{ll}F(E U R) & - \text { fuel cost; } \\ I(E U R) & - \text { investment cost; } \\ L C O E(E U R / k W) & - \text { levelized cost of energy; } \\ M(E U R) & - \text { operations and maintenance cost; } \\ P_{C H P}(M W) & - \text { power production in a CHP plant; } \\ P_{H P}(M W) & - \text { power needed for HP operation; } \\ E(M W) & - \text { electrical production; } \\ R^{2}(-) & - \text { goodness of fit; } \\ a_{i}(-) & - \text { model coefficients for the CHP power production; } \\ b_{i}(-) & - \text { model coefficients for CHP fuel input; } \\ c_{i}(-) & - \text { model coefficients for HOB fuel input; } \\ d_{i}(-) & \\ n(y e a r s) & \\ r(\%) & \end{array}$

Subscript/Superscript

CHP

- combined heat and power plant;

el

- electricity cost; 


$\begin{array}{ll}\text { Elb } & \text { - electric boiler; } \\ \text { HOB } & - \text { heat only boiler; } \\ \text { HP } & - \text { heat pump; } \\ \text { fix } & - \text { fixed O\&M cost; } \\ \text { fuel } & - \text { fuel cost; } \\ t(-) & - \text { year; } \\ \text { var } & - \text { variable O\&M cost. }\end{array}$

\section{Abstract}

This paper discusses factors associated with the decisions on energy supply plants in new or existing district heating (DH) systems. Three highly efficient energy conversion technologies were considered. The study focused on an assessment of the heat supply units, considering the economic aspects and technical limitation of the technologies. Further, risks associated with the changes in heat load profiles and fuel price volatility were investigated. The existing method for heat supply optimization was compared with a new method, suggested in this paper. The new method was based on detailed performance simulation models developed in Aspen HYSYS software and data post-processing in MATLAB. The results showed that the existing method for the heat supply optimization cannot demonstrate all the advantages of highly efficient conversion technologies. The study on the new method examined 36 plant combinations and identified eight with a levelized cost of energy (LCOE) under $0.15 \mathrm{EUR} / \mathrm{kWh}$. The results showed that an increase in the flexibility of DH provided better heat supply reliability, while increasing the heat cost. The total deviation in LCOE due to fuel and electricity price volatility was in the range of 
$1.6 \%-3.6 \%$. Further, a change of $20 \%$ in the plant investment costs induced almost the same variation in LCOE.

\section{Introduction}

The economy of district heating (DH) companies is highly dependent on heat sales. The rule is quite simple: the more heating energy is consumed by customers, the more profitable are the DH companies. This tendency was clearly explained by the authors in [1]. Today, with the new building codes and standards, a lot of attention is devoted to efficient energy use in buildings and the reduction of heat loss $[2,3]$.

DH service is quite flexible and allows the employment of different energy conversion technologies for heat energy generation. When which technology to use is in question, many issues should be considered. One scenario is when the energy production plants are already installed and in operation. Then, it is fundamental to find a solution for how the existing plants can be operated with the lowest possible annual costs. On the contrary, when planning a new DH system, the heat demands of the different target areas and the possible future development of these should be analyzed; available heat sources should also be investigated. Finally, there is an important task to determine the optimal generation units' combination, optimum configuration of the DH network, and the optimum water temperature levels [4]. In addition, economics, energy saving, and environmental impact have become more important criteria for system design and operation, more heavily burdening designers [5].

DH production units are chosen based on the scale and variation of heat demand, the local availability, costs of energy sources, and the investment cost of each technology [6]. Hence, for optimal utilization of the renewable energy and for economic reasons, the thermodynamic performance of energy production units is of major interest [7]. If the simulation approach has a 
significant influence on operation results, then the cost of utility for society and the revenue for the investor will be also influenced by quality of simulation model [8]. This means that the decision to employ different technologies has to be based on proper evaluation with the aid of relevant simulation models. In turn, this must include the variability of the system parameters, aiming to find the best performance obtainable from the match between production plants and users [9].

In liberalized energy markets, the installed utility technologies are optimized in an effort to reduce the total production cost for each individual hour of production [7] and to find the cheapest unit commitment and load dispatch satisfying the given heat, power and reserve demands using the given units [10]. This makes economy of production, together with technical aspects of technology, the main parameters that should be investigated before the final verdict is handed down.

When the combination of energy supply plants is under consideration, capital investment and operation and maintenance $(\mathrm{O} \& \mathrm{M})$ costs should be carefully examined for each production unit. The main idea here is that different fuels can be utilized depending on their availability and cost. In addition, electricity rates should be considered. According to [11], electricity rates affect the operation of combined heat and power (CHP) plants as well as heat pumps (HP) and electric boilers. At the same time, the plant running costs put extra pressure on economic decisions when annual operation is considered. The appropriate sizing of production plants is vital to achieve good levels of utilization, to ensure suitable performance for chosen systems, and to enable effective integration with existing or new DH systems [12]. Further, it should be noticed that in most cases the plant operation becomes inefficient if the energy production unit operates under a low plant load $[11,13]$. Given the high costs of installation and the tight energy saving 
constraints at which these plants are subjected, an incorrect predictive analysis can result in investment unsustainability either in economic or environmental terms $[14,15]$.

Ultimately, a possible change in heat load profiles should be taken into account. According to [16], it is expected that, in the medium term, heat load patterns can demonstrate fluctuations. The main reasons for that are: improved insulation of buildings, installation of ventilation systems with heat recovery, creation of heat islands due to growth of cities and global warming $[17,18]$ and legislation amendments. The aforementioned facts facilitate a decrease in customers' heat load profiles. On the other hand, the rise in population [19] and housing comfort levels [20] will contribute to an increase in the load to be heated. Thus, the levelling and size of the future DH demand will influence future DH operation and local DH system development [11].

The existing method of heat supply optimization that DH companies use currently is based on methodology on construction of optimal generation mix [21]. This method implies an energy unit with the highest investment cost be employed as a base load plant. In turn, this gives lover specific heat cost and higher plant efficiency [1]. This means that economy-of-size takes place and denotes energy plants with lower cost at higher production volumes as the main driving force. However, these arguments are no longer as strong, since more efficient heat generation technologies are available. Unfortunately, this method does not provide clear explanation which plant should be used by DH companies in various situations. Further, the energy efficiency of energy production units is treated as constant regardless of the load change. As mentioned before, the energy production unit operates inefficiently under a low plant load $[11,13]$.

Low DH price and ability to withstand energy efficient stand-alone heat generation solutions are the key factors that would make DH companies profitable in a long term. Therefore, 
this work aimed to propose a methodology that allows to identify the best combination of energy supply plants employing renewable energies and decreasing DH generation cost. The new method considers different input variables and operation constraints that makes it robust tool for heat energy planning.

The economic and technical aspects of heat generation were considered as well as yearly operation. In addition, the study provided information on consequences due to change in heat load patterns and fuel price volatility. In comparison to existing literature, this paper sheds light on how to combine several energy supply technologies, including significant economic data. In addition, the models used in the analysis were based on detail thermodynamic models that make this study feasible.

\section{Relevant energy supply technologies}

Different energy supply plants are available for employment in the DH system. However, it is not an easy task to decide which of these should be installed in a particular situation. Due to technological complexity and limitations in operation, their applicability decreases. Therefore, the following section focuses on the pros and cons of the analyzed energy supply plants.

\subsection{Biomass combined heat and power plant}

CHP technology is well known and proved to be reliable nowadays. This technology was put forward more than a century ago [22]. According to [23, 24] CHP systems can be classified into topping and bottoming cycle with different exploitation regimes such as heat-much mode, electricity-much mode, mixed-much mode, and stand-alone mode [25]. CHP is efficient because it avoids the large amounts of waste heat produced in typical power generation plants [26]. In comparison to other energy conversion technologies used today, CHP has one of the highest indicators and its energy efficiency can reach up to $90 \%$ leading to better utilization of primary 
energy [27]. The attractive property of a CHP plant connected to a DH network is the possibility to massively include renewable sources of energy into energy systems at a reasonable cost [28]. Biomass CHP plants are often seen as an efficient way to reduce greenhouse gases emissions due to their very low $\mathrm{CO}_{2}$ emissions level $[29,30]$.

However, there are several drawbacks associated with biomass CHP. Some biomass resources, in particular straw, contain aggressive components such as chlorine. These can lead to slagging and corrosion that reduces the security of supply for DH customers. Further, biomass fuel has a great variety of composition and therefore, different lower heating values (LHV) can affect the efficiency of CHP plants and their output [31]. These place limitations on plant operation, for example when the peak load should be covered. The slow startup of this technology requires a startup load and extra operation hours. Further, most CHP plants designed for DH purposes are characterized by very low power to heat ratio [32]. In addition, biomassbased CHP plants are widely used in regions that have ample fuel wood resources, forestry or agricultural residues. A business plan including the cost of the biomass resource collection and logistics is needed to ensure that CHP or power generation from solid biomass is economically viable [33].

\subsection{Biomass heat only boiler}

Nowadays, the modern heat only boilers (HOBs) are biomass based. Type of fuel determines which equipment should be installed for the best fuel utilization. The main advantage of such systems is their high efficiency, especially when energy recovery technology is applied. If the moisture content of the fuel is above $30-35 \%$, such as with forest wood chips, flue gas condensation should be employed. Flue gas condensation can improve the overall maximum efficiency of the plant by up to $30 \%$, depending on fuel type and the temperature of the DH water 
[34]. For plants firing wood-chips with $45-55 \%$ moisture content, the thermal efficiency of more than $100 \%$ could be reached based on LHV [35]. Biomass HOB provides the possibility to maximize $\mathrm{CO}_{2}$ savings and potentially eliminate all emissions from fossil fuel systems. The costs of biomass fuels are typically lower than the fossil fuels and such systems can therefore provide significant operational savings, which reduces the payback period [12].

The drawback of such systems is high complexity that required highly trained operation staff. Higher combustion temperatures can lead to high temperature corrosion, soot, and wear out of equipment [36]. Biomass heating systems generally have a higher initial capital cost than fossil fuel systems of equivalent rated capacity. Although biomass systems have higher upfront costs than fossil fuel boilers, if there is a need to run at low load conditions for extended periods, there are also potentially higher maintenance cost [12].

\subsection{Heat pump}

Heat pump (HP) systems offer economical alternatives to recovering heat from different sources for use in various industrial, commercial, and residential applications [37]. A DH system is a promising energy-saving measure for high-density cities, and HP systems play an essential role in such large-scale systems [38, 39]. Further, DH systems with HP technology have demonstrated significant reductions in annual energy bills [40]. Today, the most advanced technical developments in the HP field provide the opportunity to deliver heat at a temperature of $110^{\circ} \mathrm{C}$ [41-43]. According to [40,44], the large-scale HP applications based on mechanical vapor compression and absorption closed cycle principles can be successfully applied in the DH systems. 
A general advantage of HP technology is its ability to utilize energy at a low temperature level. In addition, the HP is flexible concerning the use of renewable energy, waste, and surplus heat. Compared with traditional heating technologies, HPs are more complex and have high investments costs. However, this is counterbalanced by considerable savings in operation costs [31].

The main drawback associated with HP technology is electricity use. This is particularly relevant when the electricity prices in local conditions are quite high. At the same time, the use of large HPs can be called into question due to the high carbon content in the marginal or incremental electricity generation in most industrialized regions and countries [1]. The investment cost of high temperature HP is typically the same for the different technologies, when only the HP itself is considered [31]. Economically, a simple payback period for industrial HP applications is between two and five years [44].

\subsection{Electric boiler}

Even though undesirable in new requirements, electric boilers are sometimes necessary for an energy supply to cover extreme operation situations and as a back-up plant. Therefore, some information about their operation, benefits, and drawbacks is provided. Electric boilers for DH are used to some extent in countries where electricity is occasionally available at a low price, for example in Sweden and Norway [1]. Due to its very simple design, the electric boiler is extremely reliable and easy to maintain. The operating costs are very dependent on the size of the boiler. Thus, heat production from electric boilers can only compete with other heat production units at low electricity prices [31]. If necessary, an electric boiler can also be operated as a peak load plant, even though this may be problematic from the perspective that in many countries there is a tendency for peak heat demand to coincide with the peak in electric power demand [1]. 


\section{Economic data on energy supply technologies}

This section focuses on various economic issues associated with the installation of energy production units. The presented information is based on a literature review. The aim was to identify the available economic data associated with capital investment and O\&M values for each technology. In addition, fuel prices and electricity rates were considered.

Several issues should be considered when making a decision on the installation of an energy production unit. Firstly, the technology should meet customer requirements in providing heat to the DH system. At this point, it can be noted that different customers can use a wide range of temperatures due to their various requirements. Further, heat load patterns should be taken into account. Due to changeable climate characteristics and continuous improvements in building codes and standards, the heat load patterns can show variation from year to year. On the other hand, employed energy conversion technology should be environmentally friendly and certainly display positive economy under long-term operation. Therefore, a detailed feasibility study should be carried out considering the installation of a particular system.

Normally, three economic key points should be analyzed before making an investment in a particular technology. These are as follows: capital investment costs, fixed O\&M costs, variable O\&M costs, and fuel costs.

Due to the significant amount of cost data found for each technology, corresponding tables are presented in the Appendix. The data in Appendix are organized in tables, for each technology. However, the most important information selected for the analysis is listed in Section 4.7. 
The comprehensive economic feasibility of the heat production units is impossible to gauge without fuel prices. In this study both CHP and HOB systems utilized biomass as a fuel. At the same time, electricity was required for HP operation. Hence, Table 1 summarizes the fuel prices for these technologies found in the literature for EU countries.

Table 1 Prices for biomass fuel and electricity

\section{Methodology}

In this section, the methodology for the analysis of energy supply technologies and economic evaluations is described. In this study, three state-of-the-art technologies have been chosen for the analysis. In addition, the electric boiler was considered for heat supply during extreme operation situations. For the purpose of feasibility, detailed plant models are necessary. Therefore, the simulation of energy supply sources was done in Aspen HYSYS [50] simulation software. The Aspen HYSYS simulation software is well known in process simulation and gives possibility to include different components. Some examples of application are mentioned in [5153]. For the purpose of this study, simplified plant models were developed based on detailed HYSYS models. The simplified, polynomial models were necessary to enable easier link between different plant performance data and heat load data. Detail explanation on the new method is given in Section 4.6. In addition, the analysis considered three scenarios of heat load patterns. The heat duration curves are introduced in Section 5. Based on the polynomial plant models and heat load data, the methodology for plant analysis was developed in MATLAB software [54].

\subsection{Biomass based CHP models, detailed and simplified}

The biomass CHP plant is shown in Fig. 1. 
Fig. 1 Schematic of the biomass based CHP

The LHV of biomass fuel was assumed $19 \mathrm{MJ} / \mathrm{kg}$ with a moisture content of $40 \%$. The ambient conditions were $15^{\circ} \mathrm{C}$ and 1.015 bar. After fuel combustion in the reactor, the flue gases with a temperature of $880^{\circ} \mathrm{C}$ flew in a high recovery steam generator (HRSG), where the pressurized water carrier was heated up to $540^{\circ} \mathrm{C}$. The HRSG was modeled as a three-stage-heat exchanger. These stages are an economizer, an evaporator, and a superheater. The steam turbine cycle (STC) contained a high pressure steam turbine (HPST), an intermediate pressure steam turbine (IPST), and a low pressure steam turbine (LPST). The live steam flowing from the HRSG expanded in the HPST from $540^{\circ} \mathrm{C}$ and 100 bar to $259^{\circ} \mathrm{C}$ and 12 bar. The expansion continued in the IPST to $239^{\circ} \mathrm{C}$ and 10 bar. IPST was with one extraction for DH purposes. The DH was satisfied based on consumers' required values of heat energy. Finally, in the LPST, the steam expanded to $33^{\circ} \mathrm{C}$ and 0.05 bar; after the condenser, the water was pumped back to the HRSG. The total efficiency of the CHP plant operation was $88 \%$.

The dynamic behavior of modern CHP plants is characterized by the short startup time and quick load change capability [55]. In order to ensure that operation of a CHP plant is realistic, the startup and standstill intervals were considered in the analysis. It was assumed that the CHP plant did not operate (was in standstill mode) if DH load was low for longer than 72 hours. Therefore, the three startup modes [55] were applied when the condition of plant operation was satisfied:

- Hot start after 8 hours standstill: 40 - 60 minutes;

- Warm start after 48 hours standstill: 80 - 120 minutes;

- Cold start after 120 hours standstill: 120 - 170 minutes. 
According to [12], from both a technical and an economic point of view, a biomass plant is best operated relatively continuously at between $30 \%$ and $100 \%$ of its rated output. Biomass plants do not generally respond well to rapidly varying loads or long periods at low load conditions below a minimum modulating range. Therefore, the lower bound of a CHP's heat capacity applied in this study was equal to $30 \%$ of full plant capacity.

After the model simulation was conducted in Aspen HYSYS, enough data points for defining the simplified model were obtained. Fig. 2 shows relationship between power production and DH load, and fuel consumption and DH load in CHP plant. The plant performance for three different sizes of the heat load are given in Fig. 2 These three sizes were chosen based on the maximum heat demand, see Section 5.

Fig. 2 Operational characteristics of three CHP plants with various heat capacities

From Fig. 2a the power production of a CHP plant can be described by using heat output as:

$$
P_{C H P}\left(Q_{C H P}\right)=a_{3} \cdot Q_{C H P}^{3}+a_{2} \cdot Q_{C H P}^{2}+a_{1} \cdot Q_{C H P}+a_{0}
$$

where $Q_{C H P}$ is the required heat output to the DH system and $a_{3}, a_{2}, a_{1}, a_{0}$ are model coefficients. Further, the dependencies between fuel consumption and DH load in CHP plant can be described as fifth-polynomial model for fuel input, as a function of heat output:

$$
F_{C H P}\left(Q_{C H P}\right)=b_{5} \cdot Q_{C H P}^{5}+b_{4} \cdot Q_{C H P}^{4}+b_{3} \cdot Q_{C H P}^{3}+b_{2} \cdot Q_{C H P}^{2}+b_{1} \cdot Q_{C H P}+b_{0}
$$


where $Q_{C H P}$ is required heat output to the $\mathrm{DH}$ system and $b_{5}, b_{4}, b_{3}, b_{2}, b_{1}, b_{0}$ are model coefficients. The accuracy of the curve fitting and future model ability can be measured by $R^{2}$ value. The closer $R^{2}$ value to 1 , the better the model.

Finally, based on the model data, it was possible to calculate the CHP energy efficiency as a function of the heat load. The maximum energy efficiency of CHP model was close to 0.9, for all three CHP sizes. The maximum efficiency was reached for the maximum heat load. Hence, the found CHPs' energy efficiencies fits well with data presented in Appendix, which proved the high degree of quality of the applied CHP models.

\subsection{Biomass HOB models, detailed and simplified}

Nowadays, the most advanced HOB are designed with the heat recovery of the flue gases that leads to improved efficiency.

Fig. 3 shows a layout of biomass HOB with energy recovery.

Fig. 3 Schematic of HOB

The fuel with the air was supplied to the reactor, where the combustion process took place. Further, the heat was released to heat up the DH water in the HRSG. In this study, the model of biomass HOB was constructed in a two-stage flue gas condensing system for maximum energy conversion. In the first stage, the incoming DH water was preheated by absorption HP, while in the second it was after-heated and then supplied to the HRSG of the HOB. The absorption HP was driven by high-pressure steam with ammonia as a working liquid and a water as an absorbent. In the condensing system the temperature of flue gases decreased to $35^{\circ} \mathrm{C}$ and the most of water vapor was condensed to water. The supplied water temperature to HRSG after

condensing system constituted $80^{\circ} \mathrm{C}$. In this study, both HOB and absorption HP were evaluated 
as a single unit. The return $\mathrm{DH}$ water from consumers had temperature of $50^{\circ} \mathrm{C}$ and after warming up in the $\mathrm{HOB}$ the temperature of $105^{\circ} \mathrm{C}$ was reached. Normally, the typical wood fired HOB plants are regulated in the interval of $25-100 \%$ of full capacity, without violating emission standards. The best technologies can be controlled $10-100 \%$ with fuel not exceeding $35 \%$ moisture content [31]. Therefore, the lower bound of HOB's heat capacity applied in this study was equal to $25 \%$ of full plant capacity.

In the HOB model the main interest was the relationship between fuel use and DH load. Therefore, Eq. (3) presents a simplified model of the HOB based on a detailed HYSYS model.

$$
F_{H O B}\left(Q_{H O B}\right)=c_{5} \cdot Q_{H O B}^{5}+c_{4} \cdot Q_{H O B}^{4}+c_{3} \cdot Q_{H O B}^{3}+c_{2} \cdot Q_{H O B}^{2}+c_{1} \cdot Q_{H O B}+c_{0}
$$

where $Q_{H O B}$ is required heat output to the $\mathrm{DH}$ system and $c_{5}, c_{4}, c_{3}, c_{2}, c_{1}, c_{0}$ are model coefficients.

Fig. 4 shows polynomial models for the HOB in Fig. 3.

Fig. 4. Fuel consumption versus DH load in HOB

The developed HOB models showed maximum heat efficiencies of $1.12-1.16$. This is mainly because flue gas condensation technology was used. The heat efficiencies showed match with existing literature, see Appendix, which proved that the introduced HOB models were good and reliable for further analysis.

\subsection{Vapor compression HP, detailed and simplified models}

The main issue associated with the use of HP technology in DH systems is ensuring that desired supply temperature is satisfied. This HP modification uses $\mathrm{NH}_{3}$ (ammonia/ R717) as a 
working fluid and Vilter's single-screw compressor [43]. This technology is referred to as a high temperature heat pump (HTHP) used for industrial installations.

In this study, a large mechanical heat pump (MHP) was considered for the analysis. The MHP was based on the vapor compression principle and utilized ammonia as a working fluid. The scheme of the two-stage MHP is presented in Fig. 5.

Fig. 5 MHP with two-stage compression and separation vessel

In the MHP system, the four main components of the HP, the evaporator, compressor, condenser, and expansion valve, were connected to a closed circuit. The MHP contained a separator vessel. The function of this vessel is to separate the refrigerant in the liquid and vapor. In the analyzed model the MHP was assumed to upgrade heat from residual waste water. The incoming temperature of residual water to the evaporator was $27^{\circ} \mathrm{C}$. After releasing heat in the evaporator, the temperature dropped to $24^{\circ} \mathrm{C}$. Further, the ammonia vapor was compressed in the low-pressure compressor (LPC) from 7 bar and $15^{\circ} \mathrm{C}$ to 30 bar and $167^{\circ} \mathrm{C}$. The refrigerant in the gaseous state flowed to Condenser 1, where the water from the DH network preheated up to $70^{\circ} \mathrm{C}$. After Condenser 1, the mixture of fluid and gaseous refrigerant flowed to the separator vessel. In the separation vessel the refrigerant was separated into two fractions. The liquid fraction was forwarded to the evaporator via the expansion valve, and gaseous refrigerant continued be compressed in the high-pressure compressor (HPC). The HPC compressed the working fluid from 30 bar and $66^{\circ} \mathrm{C}$ to 76 bar and $172^{\circ} \mathrm{C}$. Further, the hot vapor flowed to Condenser 2 and DH water was after-heated up to a temperature of $105^{\circ} \mathrm{C}$. Finally, the highpressure refrigerant flowed back to the separator and the cycle continued. 
The simplified model of the HP's power use can be expressed as:

$$
P_{H P}\left(Q_{H P}\right)=d_{3} \cdot Q_{H P}^{3}+d_{2} \cdot Q_{H P}^{2}+d_{1} \cdot Q_{H P}+d_{0}
$$

where $Q_{H P}$ is the required heat output to the DH system and $d_{3}, d_{2}, d_{1}, d_{0}$ are the model coefficients.

The polynomial model of the HP is depicted in Fig. 6.

Fig. 6. Power consumption versus DH load in HP

Due to low variation of heat source temperature, the coefficient of performance (COP) of the analyzed HP was almost equal to 3.3. Similar valued were found in the literature for the HP performance.

\subsection{Electric boiler}

The employed electric boiler model was described by linear dependency. The boiler control ability was adjusted between $10-100 \%$ [31] and had efficiency of $\eta=99 \%$.

\subsection{Existing method for heat supply optimization}

In this paper the new, suggested, method is compared to the existing method of heat supply optimization. The existing method implies the following assumptions: constant energy price; $0-100 \%$ control range of the plant capacities; no influence of plant size on investment cost; constant plant efficiency regardless of the plant load. This method was developed primarily for electrical energy planning and explained in details in [21]. Further, the method was adjusted to DH needs [1].

The total cost for the heat generation can be expressed as: 


$$
C=C_{f i x}+C_{v a r}
$$

where $C$ is a total annual cost which consists of an annual fixed cost, $C_{f i x}$, and a variable operating $\operatorname{cost} C_{\text {var }}$.

The specific cost for each heat unit will be:

$$
c=c_{f i x}+c_{v a r} \cdot \tau
$$

where $c$ is a specific total cost per capacity unit, $c_{f i x}$ is a specific investment cost per installed heat unit, $c_{v a r}$ is a variable cost per heat unit, $\tau$ is operation time.

The specific total cost per installed heat unit can be found as:

$$
c=C / P
$$

where $P$ is installed heat rate for each plant.

The specific investment cost can be found as:

$$
c_{f i x}=C_{f i x} / P
$$

Thus, the variable cost per heat unit can be expressed as:

$$
c_{\text {var }}=C_{\text {var }} / Q
$$

where $Q$ is annual heat supply.

The break-even times of plants operation can be found for a various number of energy production units that are taken in optimization process. Eq. (10) and Eq. (11) shows situation where three energy production plants are optimized in order to find the lowest annual total cost. The break-even times $\tau_{1,2}$ and $\tau_{2,3}$ are obtained using the basic optimization condition that stipulates that the total cost should be equal for two competing plants at each intersection: 


$$
\begin{gathered}
\tau_{1,2}=\left(c_{f i x, 2}-c_{f i x, 1}\right) /\left(c_{v a r, 1}-c_{v a r, 2}\right) \\
\tau_{2,3}=\left(c_{f i x, 3}-c_{f i x, 2}\right) /\left(c_{v a r, 2}-c_{v a r, 3}\right)
\end{gathered}
$$

\subsection{The suggested methodology for analysis of the energy supply plants}

In order to combine the plants properly, there is a need to identify the total number of

combinations. Therefore, the basic formula for the number of possible combinations of $k$ objects from a set of $n$ objects can be written as:

$$
\left(\begin{array}{l}
n \\
k
\end{array}\right)=\frac{n \cdot(n-1) \ldots(n-k+1)}{k \cdot(k-1) \ldots 1}=\frac{n !}{k ! \cdot(n-k) !}
$$

The Eq. (12) applied in this study allows finding the total number of possible plants' sets with three elements in each of them.

The method implied to use plant capacities in proportion of $20 \%, 40 \%$, and $60 \%$ of the maximum DH load (see Section 5), which makes it easier to develop combinations sets. In this study heat generation units were combined in three dimension sizes: $2.8 \mathrm{MW}$ that corresponds to $20 \%$ of the full DH load, $5.6 \mathrm{MW}$ equal to $40 \%$ of the full DH load, and $8.4 \mathrm{MW}$ equal to $60 \%$ of the DH load. One of the conditions is that a combination set should employ different technologies in it without repetitions. Another is that three plants should not have total heat capacity more than $100 \%$ of the DH load e.g. $14 \mathrm{MW}$. Therefore, under these conditions a number of generated plant combinations (PCs) by Eq. (12) was limited to 36. 
Fig. 7 shows how the plants were combined. The PCs are based on plant ability to satisfy base load. When one technology is chosen for the base load, other technologies cover the rest of the load as an intermediate and peak load plants.

Fig. 7. Analyzed combinations of energy supply sources

Fig. 7 shows three energy generation technologies with different heat outputs developed in combination sets. The color lines indicates plant's attachment to base load, intermediate load or peak load. The electric boiler was not included in Fig. 7, however, each combination has an electric boiler of $3 \mathrm{MW}$ of heat output to cover extreme operation situations and as a back-up plant. Fig. 8 introduces the information flowchart for the new method used in this analysis.

Fig. 8. Information flowchart for the new method for energy planning

\subsection{Economic evaluation}

In Section 3 the overview of the cost data for technologies and fuel prices was presented. This section introduces a technique for performing the cost analysis. In this study, the levelized cost of energy (LCOE) [56] approach was used to compare PCs. The LCOE of a given technology is the ratio of lifetime costs to lifetime energy generation, both of which are discounted back to a common year using a discount rate that reflects the average cost of capital [57]. The LCOE allows alternative technologies to be compared when different scales of operation, different investment and operating time periods, or both, exist [56].

The LCOE can simply be presented as:

$$
\text { LCOE }=\frac{\text { Total Life Cycle Cost }}{\text { Total Lifetime Energy Prodution }}
$$


The total life cycle cost in Eq. (13) includes capital investment cost, O\&M cost and fuel cost. The capital investment cost can be estimated as:

$$
I_{t}=I_{C H P}+I_{H O B}+I_{H P}+I_{E l b}
$$

where $I_{C H P}, I_{H O B}, I_{H P}, I_{E l b}$ are investment costs for the installation of CHP, HOB, HP and electric boiler.

The fixed share of O\&M includes all costs which are independent of how the plant is operated, e.g. administration, operational staff, planned and unplanned maintenance, payments for O\&M service agreements, network use of system charges, property tax, and insurance. Reinvestments within the scheduled lifetime are also included, whereas re-investments to extend the life are excluded. Variable O\&M costs included consumption of auxiliary materials (water, lubricants, fuel additives), treatment and disposal of residuals, output related repair and maintenance, and spare parts (not, however, costs covered by guarantees and insurance) [31]. Therefore, the O\&M costs can be found to be:

$$
M_{t}=C_{v a r}^{C H P}+C_{v a r}^{H O B}+C_{v a r}^{H P}+C_{v a r}^{E l b}+C_{f i x}^{C H P}+C_{f i x}^{H O B}+C_{f i x}^{H P}+C_{f i x}^{E l b}
$$

where $C_{v a r}^{C H P}, C_{v a r}^{H O B}, C_{v a r}^{H P}, C_{v a r}^{E l b}$ are variable O\&M costs, and $C_{f i x}^{C H P}, C_{f i x}^{H O B}, C_{f i x}^{H P}, C_{f i x}^{E l b}$ are fixed O\&M costs for $\mathrm{CHP}, \mathrm{HOB}, \mathrm{HP}$ and electric boiler.

The fuel consumption cost was evaluated as a sum of biomass fuel consumed by CHP and $\mathrm{HOB}$, and electricity needed for the operation of the electric boiler and HP:

$$
F_{t}=C_{f u e l}^{C H P}+C_{f u e l}^{H O B}+C_{e l}^{H P}+C_{e l}^{E l b}
$$


where $C_{\text {fuel }}^{C H P}, C_{\text {fuel }}^{H O B}$ present the fuel cost for operation of the CHP, HOB, HP and electric boiler. The allocation of the CHP's fuel cost between thermal production and electrical production was based on an energy method [58]:

$$
f_{Q}=Q /(Q+E)
$$

where $Q$ and $E$ represent thermal and electrical production.

Finally, including all the costs, Eq. (13) can be rewritten as:

$$
L C O E=\frac{\sum_{t=1}^{n} \frac{I_{t}+M_{t}+F_{t}}{(1+r)^{t}}}{\sum_{t=1}^{n} \frac{Q_{t}}{(1+r)^{t}}}
$$

where $I_{t}$ is investment expenditure in the year $t ; M_{t}$ is O\&M expenditure in the year $t ; F_{t}$ is fuel expenditure in the year $t$; $Q_{t}$ is heat generation in the year $t ; r$ is a discount rate; and $n$ is the life of the system.

The discount rate is meant to reflect the loss of utility from deferred consumption and the degree of systematic risk of the project [59]. The discount rate to be used in socio-economic analyses in the energy sector in Norway is determined by the Norwegian Water Resources and Energy Directorate (NVE) [60], based on instructions from the Ministry of Finance. DH is normally considered an investment with low economic risks [1], the NVE has stated to apply discount rate of $4.0-6.5 \%$ for bio-based DH systems [61, 62]. 
The technical life of technologies can be adopted from [31, 33, 63]; for biomass CHP it is typically $20-25$ years, for biomass HOB and large-scale vapor compression HP and electric boiler, this value is 20 years [31].

Based on the literature review presented in Section 3, the investment and O\&M costs given in Table 2 were selected for this analysis. However, there could be some uncertainty in these values. Therefore, in order to evaluate consequences due to inaccurate cost data, the uncertainty analysis is presented in Section 6.

Table 2. Investment and O\&M costs used in the analysis

After an evaluation of different prices of biomass fuel and electricity rates presented in Table 1, the biomass fuel price was chosen as $75 \mathrm{EUR} /$ tonne and the electricity price as 0.12 EUR/kWh.

\section{Case study}

The analysis of different combinations of energy supply technologies was based on heat energy demand measured on the university campus. The required supply and return temperature levels in the $\mathrm{DH}$ system were assumed to be $105-50^{\circ} \mathrm{C}$. In this study, three heat demand profiles were considered to illustrate the influence of the different load distributions. The analyzed duration curves are depicted in Fig. 9.

Fig. 9 Heat duration curves

Case 1 in Fig. 9 presented the heat duration curve during a regular year in the analyzed location and was used as a reference year. Case 2 presented the heat duration curve under a higher 
occupancy level and lower outdoor temperature. The heat duration curves in Case 1 and Case 2 were measured on the university campus. Case 3 represents the situation for future energy use, taking into account newly-built passive houses and nearly zero energy buildings (nZEB) with low heat energy use throughout the year and occasional high peaks. Case 3 is the result of an assumption and is characterized by a decrease in heating energy use of $22.17 \%$ in comparison with the reference year. The heat load characteristics of the analyzed cases are summarized in Table 3.

Table 3. Heat load characteristics

\section{Results}

Energy planning results by using the existing method of heat supply optimization are shown first. Afterwards, the findings from the new method of energy planning are shown.

\subsection{Results on the existing method}

The main idea behind different optimization techniques is to find the solution that best satisfies DH operation from both technical and economic viewpoints. Therefore, the existing method for heat supply optimization balances operation cost and investment cost to achieve the lowest total annual cost. This method is explained in Section 4.5. Fig. 10 introduces the existing plant optimization method.

Fig. 10. The linear cost characteristics for three plant model is shown in the upper diagram and the corresponding optimal division of plant capacities are shown in the lower duration diagram 
Fig. 10 shows that the electric boiler has the lowest investment cost and, therefore, it is beneficial be utilized as a peak load plant from. The intermediate load should be covered by HP and the base load by HOB. Further, it can be noted that CHP is not a relevant plant according to the existing method, because the investment is too high. In reality, it is well known that CHP is reliable provider of heat supply and it is beneficial to run it as a base load plant. In Fig. 10, the plant capacities could be distributed as follows: for the peak load plant an electric boiler of 8.48 MW maximum rate, for the intermediate load plant HP of $4.62 \mathrm{MW}$, and for the base load plant HOB of $0.81 \mathrm{MW}$.

The sensitivity analysis of the existing optimization method (Fig. 10) was performed in order to estimate the robustness of the method regarding the change in heat load. Table 4 shows the sensitivity results.

Table 4. Sensitivity of the existing optimization method due to different load profiles

From Table 4 it can be seen that change in heat load induced significant variation in the plant heat capacities. For the electric boiler the induced change was between $1 \%$ and $23 \%$, for HP was $55 \%$ and $70 \%$, and for $\mathrm{HOB}$ was between $7 \%$ and $22 \%$ due to load change. This showed that this method is very sensitive to changes in heat load profile. In turn, this can lead to low load factor for operated plants and further effect the DH price.

The uncertainty due to change in investment cost in the range of $\pm 10 \%$ showed that electric boiler was not sensitive, which lead to negligible change in DH price of less than $1 \%$. However, HP and HOB were more effected. The change in HP's investment cost induced $+9.6 \%$ $--12 \%$ change in DH cost. For HOB these values were even higher and constituted -22\% $+18 \%$. The effect due to multiple uncertainty induced change of $-11 \%-+11.4 \%$ on $\mathrm{DH}$ cost or 
$\pm 0.01 \mathrm{EUR} / \mathrm{kWh}$ for both reduction and increase in investment cost. In addition, these lead to change in heat capacities of selected plants. Hence, the method is also sensitive to variation in investment cost.

The uncertainty due to change in energy cost for chosen plants was carried out in the range of $\pm 10 \%$. The largest change in DH cost induced the HP $(+7.61 \%--6.79 \%)$. For the HOB these values were in the range of $-2.2 \%-+2.7 \%$, while for the electric boiler $-3.4 \%-+3.5 \%$. However, the impact due to multiple uncertainty showed $1 \%$ change in DH cost. As it can be seen, the change in the investment cost induced larger change in DH cost than change in energy cost. This means that existing method of heat supply optimization is sensitive to change in investment cost of analyzed technologies.

The conclusion from the above analysis was that the existing method was sensitive to variations in heat load profiles. This means that any future change in heat demand would influence the heat cost. Further, some expensive technologies such as CHP might be excluded due to high investment cost. Finally, it does not show how DH should be equipped and operated over a long term in order to minimize the annual cost of heat supply [1].

\subsection{Results on the new method}

The entire approach for the new method was introduced in Section 4.6. and 4.7. The most relevant results are presented here. Fig. 11 present LCOE for different combinations of energy supply technologies, based on the heating load profile marked as Case 1. Under the reference

year, the LCOE varied from $0.085-2.554 \mathrm{EUR} / \mathrm{kWh}$. Therefore, for the purpose of better representation and further analysis, the found values were sorted in two categories: lower than 0.2 EUR/kWh and higher than 0.2 EUR/kWh. According to [57], the cost for electricity generation in 
Europe varies from low $0.06 \mathrm{EUR} / \mathrm{kWh}$ to a high of $0.19 \mathrm{EUR} / \mathrm{kWh}$, depending on technology and local conditions. Therefore, Fig. 11 shows the LCOE results for the analyzed PCs that are competitive with power generation cost and, consequently, with the direct electric heating.

Fig. 11. Low LCOE and fuel cost in these plant combinations

In this study, it was assumed that the electric boiler would be used to cover the heat load in the $\mathrm{DH}$ system due to limitations in the combined operation of HP, CHP, and HOB and during extreme operation situations. From Fig.11a it can be seen that heat energy produced by electric boiler constitutes a high portion of the LCOE. Due to the high value of O\&M cost, the operation of the electric boiler makes DH uncompetitive in comparison to direct electric heating. Next, it can be noticed that the HP's contribution to the LCOE was relatively low for presented plant combinations. From this point, it can be concluded that presented heat capacities of the HP fits well to the analyzed PCs. The exception was combination PC25, where the 8.4MW HP was operated as a peak load plant. This means that the HP should not be used as a peak load plant with a high installed heat rate.

Fig. 11b shows again that the highest fuel cost of each combination was due to operation of electric boiler. The exceptions were PC2 and PC3, where the HOB was operated as an intermediate load plant. In addition, PC1, PC14, and PC25 operated without electric boiler. Due to high COP of the HP, the electricity use was low in comparison to total LCOE value presented in Fig. 11a. In the countries with low electricity prices, like in Scandinavia, the employment of the HP for heat supply purpose is a good option of efficient heat energy supply. The fuel use for 
the CHP was low, even for configuration where its heat load share was $60 \%$. The similar trend was found for the HOB operation.

As it was highlighted earlier, the electric boiler was used during extreme operation situations. Fig. 12 shows combined operation of energy supply plants based on PC28, where the HOB was used as base load plant covering $20 \%$ of the maximum heat demand, the HP was used to cover the intermediate load covering $40 \%$ of the maximum load, and the CHP was utilized to cover the peak load with $20 \%$ of the maximum load.

Fig. 12 Hourly heat rate distribution for the PC28

From Fig. 12 it can be seen that due to limitations in CHP operation, see Section 4.1, the electric boiler was used to cover DH load when CHP was in standstill mode. In general, to run electric boiler is convenient due to simplicity and no limitations in operation regimes. However, in a long-term operation this can lead to an increase in DH price, which existing and new customers consider impermissible.

The second part of PCs consist of combinations where the LCOE values were higher than 0.2 EUR/kWh, see Fig. 13.

Fig. 13 High LCOE

It was found that the contribution of the electric boiler to LCOE was equal in all combinations. This means that it was not operated. These values present the investment cost for this technology. Next, the high values of the LCOE for HOB and HP are due to the low heat load factor. However, in the case of CHP, the low heat load factor was subsidized by electricity 
production and the corresponding heat allocation factor of utilized fuel. Therefore, there is no high discrepancy between CHPs' cost in the LCOE and these values are very low in all PCs. PC13 showed the highest value of LCOE. The reason for this is the same as for the PC25, where the HP with the high heat capacity was operated for the peak load plant.

Changes in the LCOE due to different heat load patterns were also investigated. The analysis was performed for combinations that have low LCOE and introduced in Fig. 11.

Fig. 14 present the LCOE for different heat load patterns and different combinations of energy supply technology. To recall, Case 2 introduces the scenario where the heat duration curve was under high occupancy and lower outdoor temperatures, Case 3 shows scenario where heat duration curve is constructed for future building stock.

Fig. 14 LCOE values for analyzed scenarios

In order to stay competitive in the energy market, the heat generation cost should be lower than alternatives. At this point, this means that the heat generation cost should be lower than the electricity production, to avoid switching to direct electric heating. As can be seen from Fig. 14, several combinations could be highlighted as being competitive in a long-term perspective. These combinations are: PC5, PC30, PC34 and PC36. Four additional combinations, PC1, PC9, PC11 and PC14, could be underlined as alternatives with LCOE values lower than $0.15 \mathrm{EUR} / \mathrm{kWh}$. It can be noticed that all these combinations have small CHP as a peak load plant. The exception is combination PC14, where large HOB was utilized for this purpose. Further, in comparison to all the PCs presented in Fig. 7, the above-mentioned combinations found the lowest LCOE values under the duration curve of Case 2. This means that the heat load factor increased, which 
provided better energy utilization in the aforementioned combinations. The discovered plant sizes fitted perfectly to the required DH loads.

Among eight PCs (PC1, PC5, PC9, PC11, PC14, PC30, PC34, PC36) only one employed CHP as a base load plant. In addition, its heat capacity was only $2.8 \mathrm{MW}$. At the same time different dimensions of HOB and HP were utilized for the base load plant. For intermediate load plants, the trend was similar, while for peak load plants most of the combinations employed the small CHP. The trend for peak load plants is due to application of CHP's allocation method.

The summary of LCOE values under different heat load profiles can be seen in Table 5.

Table 5 Heat generation cost under different load profiles

Table 5 shows that the variation in heat generation cost due to the change in heat load patterns was in the range of $12.2-25.2 \%$ or $0.017-0.031 \mathrm{EUR} / \mathrm{kWh}$ of heat. The lowest differences were found for the combinations PC14 and PC30. At this point it could be concluded that these two combinations are the best solution for customers due to the smallest change in DH cost under different heat loads. However, combinations PC5 and PC36 should be highlighted as because they showed generation cost reduction for both an increase and decrease in DH load. In PC36, 8.4 MW HOB was employed for the base load plant, 2.8 MW CHP covered the intermediate load and 2.8 MW HP was used for the peak load. Meanwhile, PC5 included the following plants: HP of 2.8 MW for the base load plant, HOB of 8.4 MW for the intermediate load and CHP of 2.8 MW for the peak load. The combinations presented in Table 5 showed the lowest LCOE for different heat load profiles among all the 36 combinations. This is very important, since employing these combinations means that DH customers would pay for consumed heat based on optimal operation of the heat production units. 
Fig. 15 shows relationship between the LCOE and system efficiency for the different PCs under different heat load profiles.

Fig 15 LCOE and system efficiency for different heat supply options under three heat loads

Fig. 15 shows that plant combinations PC11 and PC30 are more energy efficient under different heat loads than other combinations. As it found before, the PC30 and PC14 had the lowest difference in values of LCOE under different heat loads, see Table 5. However, Fig. 15 shows that in terms of energy input per delivered heat, the PC30 is more efficient than PC14. Apart from PC30, the low value was found for combination PC11. The reason for this is that both PC11 and PC30 employed large HP for base load and intermediate load, respectively.

\subsection{Uncertainties due to fuel price volatility, variation in investment cost, and model}

quality

The uncertainty analysis performed in this section was executed for eight PCs with low LCOE and showed in Table 5. The analysis was based on values from the literature review and presented in Table 1. The following fuel prices were considered: the minimum for electricity was 0.113 EUR/kWh, for wood chips was $40 \mathrm{EUR} / \mathrm{kWh}$, while the maximum for electricity was 0.127 EUR/kWh and for wood chips $136 \mathrm{EUR} / \mathrm{kWh}$.

The analysis found that the highest variation in total LCOE had combinations where the HOB was operated as an intermediate load plant. This mean that increase in the fuel price would have negative effect on LCOE for this technology. The total deviation in LCOE values for the presented PCs due to price volatility was in the rage of $1.6 \%-3.6 \%$ or $0.002-0.005 \mathrm{EUR} / \mathrm{kWh}$. The largest deviation for the CHP fuel cost was found in combinations where the CHP was 
operated as an intermediate load plant (PC1, PC6 PC14, and PC25), while the smallest deviation was found where the CHP was operated for the peak load. The largest deviations for the HOB fuel cost were found for the HOB operated as the intermediate load plant for small and intermediate heat capacities. Further, operation of the HOB as a base load plant showed the smallest variance in cost. In comparison to the results found for the CHP and the HOB, the consequences of the HP's price variation were minor in the analyzed range. One of the reasons for this is that the cost foundation for electricity production and wood chips collection is different.

The uncertainty due to variation in investment cost showed that the increase in the CHP's investment cost by $20 \%$ induced changes in the LCOE by $15-16 \%$ for the analyzed combinations. When the CHP's investment cost were decreased by $20 \%$, the change in LCOE constituted around 19\%. In comparison to the CHP, the change in investment cost for the HP and the HOB had similar trend. The increase and decrease in the HP's investment cost by $20 \%$ led to change in total annual cost by around $14-17 \%$. For the HOB these values were in the range of $14-20 \%$. Hence, underestimation of investment cost can lead to significant changes in LCOE values for these technologies.

The introduced energy plant models presented Section 4 were simplified by using polynomial models as shown in Fig. 2, Fig. 4, and Fig. 6. Even though the obtained goodness of fit $\left(R^{2}\right)$ was high, some uncertainty could take place.

The uncertainty due to model quality showed that The HP's model had larger effect on LCOE in comparison to the CHP and the HOB model. The deviation in the HP model in the range of $\pm 10 \%$ induced a change in LCOE by $1.42-4.7 \%$. In the case of the HOB and the CHP models, the consequences were smaller, around $1 \%$. The impact of multiple uncertainties 
simultaneously induced changes in the range of $1 \%$. The conclusion is that the introduced models proved to be accurate enough for this analysis.

\section{Discussion}

The existing method of heat supply optimization is found to be simple way to deal with all the costs and operation issues. A number of additional important factors affecting plant operation are missing. It was found that the method is sensitive to change in heat load profiles. In turn, this could lead to low load factor for operated plants and further increase the DH cost. Further, the calculated DH cost showed that, with the decrease in heat load, the DH cost decreases. However, this is not always the case due to a possible mismatch in plants' operation. This means that more operation hours are required to fulfill the same DH load, and an increase in $\mathrm{DH}$ cost is inevitable. In addition, the existing method is also sensitive to variation in investment cost, while the variation in energy cost induced minor changes to DH cost. All these cause misleading results, affecting DH price foundation. Further, it is very simplified with respect to real sizes, operation times, and actual plant performance. In comparison to the existing methodology, the new method suggested by the authors is more sophisticated and involves deeper analysis.

The analysis of found results for the new method showed that the operation of electric boiler can be avoided and DH companies should eliminate this technology from the DH system. In all the analyzed combinations electric boiler operation constituted from 26 to 790 hours of intermittent operation at full heat capacity. As an alternative to this, the thermal energy storage (TES) could be considered. In addition, employing TES could lead to increase in heat load factor for intermediate and peak load plants. 
All the PCs showed high LCOE values due to operation of electric boiler. The LCOE remained high even when electric boiler was not put in operation. The reason for this might be the high value of the fixed O\&M cost used in the analysis. This value was adopted from technical report [31] with reference in 2012 year. It can be doubted about meaningfulness of this value. However, the report dated two years earlier showed this value in the same range, which makes adopted value be reasonable. Therefore, some changes in this value might change the results of the study. However, any decrease of this high value of the fixed O\&M cost would give a decrease in the $\mathrm{DH}$ cost.

Further, it was not appropriate to conclude that all the combinations presented in Fig. 13 were not competitive with direct electric heating. As previously discussed, the found values are mainly due to actual operation and the low heat load factor facing those combinations. Hence, at this point, it is possible to look at those combinations from an angle of future development and extension of DH systems.

The fuel between heat and power production was allocated by the energy method. In turn, this made the CHP operation highly efficient due to the subsidizing of low heat load by electricity load and further fuel allocation to power production. This showed that CHP operation is efficient as a peak load plant. However, a number of technical allocation methods were developed and used in different countries. Therefore, the possible deviations in LCOE might be present due to the application of different allocation methods.

The example of the existing method of heat supply optimization found that it was inappropriate to utilize CHP due to its high investment cost. However, the new method showed the opposite. The small CHP plants could be employed for peak load operation. This is a good observation, since it concurs with Directive 2004/8/EC [64] on the promotion of highly-efficient 
cogeneration. The more CHP is used, the more primary energy is saved and the higher the security of the energy supply.

If one considers the four technologies discussed in this study, modern HOBs are shown to be very effective. In comparison to other technologies, their linear cost characteristic could show a decrease with an increase in operation hours. This provides the possibility to employ a single HOB for annual operation. However, the employment of a single plant decreases security of supply in the DH systems. To avoid this, the need arises for several heat production units. Hence, the cost difference of utilizing four plants would always be greater than with three or two. Therefore, it can be concluded that the heat generation cost increases with the increase in DH's flexibility and reliability of supply.

\section{Conclusion}

In this paper, the economic issues associated with the decision of choice of combination of heat production units were analyzed. The study focused on the situation when there is a need to construct a set of plants for a new or existing DH system. Three heat duration curves presenting different load patterns in the DH system, together with three highly efficient energy conversion technologies, were considered. The existing method of heat supply optimization was compared to the new method.

The results from the new method found that the operation of an electric boiler led to a high value of LCOE, in spite of the fact that it was operated sporadically and the maximum heat output was $3 \mathrm{MW}$ of heat. Next, one should consider electricity rates, since few countries have cheap electricity as in the case of Norway and Sweden. This revealed that the operation of an 
electric boiler is rather expensive and should be kept to the minimum. In addition, policy makers should provide legislative framework to ban this technology from DH.

The study identified sixteen PCs with the LCOE under 0.2 EUR/kWh. However, not all of these were found insensitive to changes in heat load profiles. Further, eight PCs were selected as those with low sensitivity to heat load variation and LCOE under 0.15 EUR/kWh (PC, PC5, PC9, PC11, PC14, PC30, PC34 and PC36). It was noted that six of those have small CHP as a peak load plant. However, it was opposite compared what the existing method suggested. Among the eight combinations, only one employed CHP as a base load plant with a heat capacity of $2.8 \mathrm{MW}$. At the same time, HOB and HP technologies utilized all their sizes for the base load plant. For intermediate load plants, the trend was similar, while for peak load plants most of the combinations employed a small CHP. It was concluded that the operation of a large HP for the peak should be avoided due to the low heat load factor and high investment cost.

The change in heat load profiles showed that, with the increase in heat energy use (Case 2), the mentioned eight combinations showed the lowest LCOE. This means that the heat load factor increased, which provided better energy utilization. The found plant sizes fitted perfectly to satisfy the required DH loads. The lowest difference in the LCOE under different heat loads were found for the combination PC14 and PC30. These two combinations were the best solution due to smallest change in DH cost under different heat loads. The normal trend of DH cost was increase over the years due to change in heat load, however, PC5 and PC36 showed that DH generation cost could be lowered. This was a good finding for future development of DH and for customers due to protection against increase in price. 
The analysis on system efficiency found the most rational utilization of energy input under different heat loads had combinations PC11 and PC30. The main reason for this is that large HP was used in these combinations to satisfy the base load and intermediate load.

The uncertainty in fuel price meant that the biggest variation in the total LCOE was found in combinations in which the HOB was operated as an intermediate load plant. This means that an increase in fuel price will have a negative effect on LCOE for this technology employed for intermediate load. The total deviation in LCOE values for presented combinations due to price variation was in the range of $1.6 \%-3.6 \%$ or $0.002-0.005 \mathrm{EUR} / \mathrm{kWh}$. The consequences of price variation for $\mathrm{HP}$ are smaller than for $\mathrm{CHP}$ and $\mathrm{HOB}$ in the analyzed range. One of the reasons for this was that the cost foundation is different for electricity production and for wood chips collection. However, in some countries electricity rates are rather high and a normal trend is for them to increase over time. In turn, this can lead to an additional portion of O\&M cost when HP technology is chosen for operation.

The uncertainty in PCs due to changes in investment cost in the range of $\pm 20 \%$ has an effect of $14-20 \%$ on LCOE. Hence, underestimation of investment cost can lead to significant changes in LCOE values for these technologies.

The uncertainty due to model quality meant that the HP model has a larger effect on LCOE in comparison to CHP and HOB. The deviation in the range of $\pm 10 \%$ induced a change in LCOE of $1.42-4.7 \%$. In the case of HOB and CHP models, the consequences were smaller, around $1 \%$. The impact of multiple uncertainties simultaneously found changes in the range of 4 $-6 \%$. The conclusion is that the presented models and the analysis approach proved to be sufficiently accurate for the purpose of this study. Consequently, the results and conclusions might be treated as reliable. 


\section{Acknowledgement}

The authors appreciate the support of funding from the Department of Energy and Process Engineering of the Norwegian University of Science and Technology.

\section{Appendix}

Table 6 - Table 9 provide a summary of different costs for the following technologies: biomass HOB, CHP, HP and electric boiler. The presented data is given based on LHV of fuels.

Table 6 Investment and O\&M costs for biomass HOB

Table 7 Investment and O\&M costs for biomass CHP

Table 8 Investment and O\&M costs for HP

Table 9 Investment and O\&M costs for electric boiler

\section{References}

[1] Frederiksen S, Werner S. District heating and cooling. Studentlitteratur; Lund, Sweden, 2013, $586 \mathrm{p}$.

[2] European Commission. Climate action. Available from: http://ec.europa.eu/climateaction. [Accessed 27th October 2015].

[3] EC. Directive 2002/91/EC of the European Parliament and of the Council of 16 December 2002 on the energy performance of buildings.

[4] Benonysson A, Bøhm B, Ravn HF. Operational optimization in a district heating system. Energ Convers Manage 1995;36(5):297-314.

[5] Yokoyama R, Shinano Y, Taniguchi S, Ohkura M, Wakui T. Optimization of energy supply systems by MILP branch and bound method in consideration of hierarchical relationship between design and operation. Energ Convers Manage 2015;92(0):92-104. 
[6] Truong NL, Gustavsson L. Cost and primary energy efficiency of small-scale district heating systems. Appl Energ 2014;130(0):419-427.[7] Ommen T, Markussen WB, Elmegaard B. Heat pumps in combined heat and power systems. Energy 2014;76(0): 989-1000.

[8] Ommen T, Markussen WB, Elmegaard B. Comparison of linear, mixed integer and non-linear programming methods in energy system dispatch modelling. Energy 2014;74(0):109-118.

[9] Pini Prato A, Strobino F, Broccardo M, Parodi Giusino L. Integrated management of cogeneration plants and district heating networks. Appl Energ 2012;97(0):590-600.

[10] Grohnheit PE. Modelling CHP within a national power system. Energ Policy 1993;21(4):418-429.

[11] Åberg M, Widén J, Henning D. Sensitivity of district heating system operation to heat demand reductions and electricity price variations: A Swedish example. Energy 2012;41(1):525540 .

[12] Carbon Trust. Biomass heating. A practical guide for potential users. In-depth guide CTG012. 2009: UK. Available from: http://www.forestry.gov.uk/pdf/eng-yh-carbontrustbiomass-09.pdf/\$file/eng-yh-carbontrust-biomass-09.pdf [Accessed 27th October 2015].

[13] Tereshchenko T, Nord N. Implementation of CCPP for energy supply of future building stock. Appl Energ 2015;155(0):753-765.

[14] De Paepe M, Mertens D. Combined heat and power in a liberalised energy market. Energ Convers Manage 2007;48(9):2542-2555.

[15] Gebremedhin A, Moshfegh B. Modelling and optimization of district heating and industrial energy system - an approach to a locally deregulated heat market. Int J Energ Res 2004;28(5):411-422.

[16] European Union. EU Energy, transport and GHG emissions trends to 2050: reference scenario 2013. Luxembourg: European Union; 2014.

[17] Wang H, Chen Q. Impact of climate change heating and cooling energy use in buildings in the United States. Energ Buildings 2014;82(0):428-436.

[18] Berger T, Amann C, Formayer H, Korjenic A, Pospischal B, Neururer C, Smutny R. Impacts of climate change upon cooling and heating energy demand of office buildings in Vienna, Austria. Energ Buildings, 2014; 80(0): 517-530.

[19] European Commission. EU employment and social situation. Quarterly review: March 2013. Special supplement on demographic trends. Luxembourg: European Commission; 2013.

[20] DG for Energy and Transport. Labelling and other measures for heating systems in dwellings: final technical report. Brussels: European Commission; 2002. Available from: http://www.eci.ox.ac.uk/research/energy/downloads/eusaveheating/fullreport.pdf [Accessed 27th October 2015]. 
[21] Stoughton NM, Chen RC, Lee ST. Direct Construction of Optimal Generation Mix. Power Apparatus and Systems, IEEE Transactions on, 1980. PAS-99(2): p. 753-759.

[22] Rosen MA, Le MN, Dincer I. Efficiency analysis of a cogeneration and district energy system. Appl Therm Eng 2005;25(1):147-159.

[23] Hinrichs RA, Kleinbach M. Energy, its use and the environment. New York, U.S.: Brook Cole; 2002.

[24] Moran MJ, Shapiro HN. Fundamentals of engineering thermodynamics. Hoboken, N.J.: Wiley; 2010. XI, 725 s. : ill.

[25] EDUCOGEN. The European Educational Tool on Cogeneration. 2nd ed.; 2001. p. 176. Available from: http://www.uned.es/experto-energia/EDUCOGEN_Tool.pdf [Accessed 27th October 2015].

[26] Rezaie B, Rosen MA. District heating and cooling: Review of technology and potential enhancements. Appl Energ 2012;93(0):2-10.

[27] Gustafsson J, Delsing J, van Deventer J. Improved district heating substation efficiency with a new control strategy. Appl Energ 2010;87(6):1996-2004.

[28] Sartor K, Quoilin S, Dewallef P. Simulation and optimization of a CHP biomass plant and district heating network. Appl Energ 2014;130(0):474-483.

[29] Varun, Bhat IK, Prakash R. LCA of renewable energy for electricity generation systems - A review. Renew Sust Energ Rev 2009;13(5):1067-1073.

[30] Lund H, Möller B, Mathiesen BV, Dyrelund A. The role of district heating in future renewable energy systems. Energy 2010;35(3):1381-1390.

[31] Energy Styrelsen. Technology data for energy plants. Generation of electricity and district heating, energy storage and energy carrier generation and conversion. ISBN 978-87-7844-931-3. 2012. p. 211. Available from:

http://www.energinet.dk/SiteCollectionDocuments/Danske\%20dokumenter/Forskning/Technolog y_data_for_energy_plants.pdf [Accessed 27th October 2015].

[32] U.S. Environmental Protection Agency. Combined Heat and Power Partnership. Catalog of CHP technologies; 2015: U.S. p. 131. Available from: http://www.epa.gov/chp/documents/catalog_chptech_full.pdf [Accessed 27th October 2015].

[33] Lako P. Biomass for heat and power. IEA ETSAP - Technology Brief E05. Energy Technology Systems Analysis Programme; 2010. Available from: http://www.etsap.org/EtechDS/PDF/E05-Biomass\%20for\%20HP-GS-AD-gct.pdf [Accessed 27th October 2015].

[34] Lava-rapport, fjärrvärmebyrån sverige ab. Technical report; 2009. Available from: http://www.svenskfjarrvarme.se/ [Accessed 27th October 2015]. 
[35] Danish District Heating Association. Available from:

http://www.danskfjernvarme.dk/sitetools/english [Accessed 27th October 2015].

[36] Oksa M, Tuurna S, Varis T. Increased lifetime for biomass and waste to energy power plant boilers with HVOF coatings: High temperature corrosion testing under chlorine-containing molten salt. J Therm Spray Techn 2013;22(5):783-796.

[37] Ajah AN, Mesbah A, Grievink J, Herder PM, Falcao PW, Wennekes S. On the robustness, effectiveness and reliability of chemical and mechanical heat pumps for low-temperature heat source district heating: A comparative simulation-based analysis and evaluation. Energy 2008;33(6):908-929.

[38] Eriksson M, Vamling L. Future use of heat pumps in Swedish district heating systems: Short- and long-term impact of policy instruments and planned investments. Appl Energ 2007;84(12):1240-1257.

[39] Nagota T, Shimoda Y, Mizuno M. Verification of the energy-saving effect of the district heating and cooling system - Simulation of an electric-driven heat pump system. Energ Buildings 2008;40(5):732-741.

[40] Chua KJ, Chou SK, Yang WM. Advances in heat pump systems: A review. Appl Energ 2010;87(12):3611-3624.

[41] Chung Y, Kim BJ, Yeo YK, Song HK. Optimal design of a chemical heat pump using the 2propanol/acetone/hydrogen system. Energy 1997;22(5):525-536.

[42] The International Energy Agency (IEA). Heat pump centre. Available from: http://www.heatpumpcentre.org/ [Accessed 27th October 2015].

[43] Blarke MB. Towards an intermittency-friendly energy system: Comparing electric boilers and heat pumps in distributed cogeneration. Appl Energ 2012;91(1):349-365.

[44] U.S. Department of Energy. A Best Practices SteamTechnical Brief. Industrial Heat Pumps for Steam and Fuel Savings. DOE/GO-102003-1735, U.S. Department of Energy. Energy Efficiency and Renewable Energy: Washington; 2003. Available from: http://www1.eere.energy.gov/manufacturing/tech_assistance/pdfs/heatpump.pdf [Accessed 27th October 2015].

[45] Eurostat. Statistics Explained. Half-yearly electricity and gas prices, first half of year, 20112013. Available from: http://ec.europa.eu/eurostat/statistics-explained/index.php/File:Halfyearly_electricity_and_gas_prices,_first_half_of_year,_2011\%E2\%80\%9313_(EUR_per_kWh)_ YB14.png [Accessed 27th October 2015]. 
[46] Bakos GC, Tsioliaridou E, Potolias C. Technoeconomic assessment and strategic analysis of heat and power co-generation (CHP) from biomass in Greece. Biomass Bioenerg 2008;32(6):558-567.

[47] AIEL. Legna e cippato: produzione, requisiti qualitativi e compravendita; 2009. Available from: www.biomasstradecentre2.eu [Accessed 27th October 2015].

[48] Bernetti I, Fagarazzi C. Valutazione della domanda di biocombustibili solidi (legno cippato) ell'area dell'Appennino Pistoiese, ISBN 10: 88-7957-287-3; 2009. Available from: www.arsia.toscana.it [Accessed 27th October 2015].

[49] Prislan P, Krajnc N, Jemec T, Piškur M. Monitoring of wood fuel prices in Slovenia, Austria, Italy, Croatia, Romania, Germany, Spain and Ireland. Biomass Trade Centre, Report No. 6; 2014. Available from: http://www.biomasstradecentre2.eu/wood-fuel-prices/ [Accessed 27th October 2015].

[50] Aspen HYSYS. (Version 7.3) AspenTech. Available from: http://www.aspentech.com [Accessed 27th October 2015].

[51] Tsay M.-T. Applying the multi-objective approach for operation strategy of cogeneration systems under environmental constraints. Int J Elec Power 2003;25(3):219-226.

[52] Gonzalez Chapa MA, Vega Galaz JR. An economic dispatch algorithm for cogeneration systems. In: Power Engineering Society General Meeting; 2004. IEEE.

[53] Chen S.-L, Tsay M.-T, Gow H-J. Scheduling of cogeneration plants considering electricity wheeling using enhanced immune algorithm. Int J Elec Power 2005;27(1):31-38.

[54] MATLAB. (Version R2014a) MathWorks. Available from: http://www.mathworks.se (Accessed 27th October 2015).

[55] Kehlhofer R. Combined-cycle gas \& steam turbine power plants. Tulsa, Okla.: PennWell; 2009. xix, 434 s. : ill.

[56] Short W, Packey DJ, Holt T. A manual for the economic evaluation of energy efficiency and renewable energy technologies. University Press of the Pacific; 2005.

[57] International Renewable Energy Agency (IRENA). Renewable power generation cost in 2014. Germany; 2015. Available from: www.irena.org/publications. [Accessed 27th October 2015].

[58] Tereshchenko T, Nord N. Uncertainty of the allocation factors of heat and electricity production of combined cycle power plant. Appl Therm Eng 2015;76(0):410-422.

[59] Ferran E, Ho LC. Principles of corporate finance law. Oxford: Oxford University Press; 2014. [60] Norwegian Water Resources and Energy Directorate (Norges vassdrags- og energidirektorat). Available from: http://www.nve.no/en/ [Accessed 27th October 2015]. 
[61] Norges vassdrags- og energidirektorat (NVE). Samfunns økonomisk analyse av energiprosjekter [Socio-economic analysis of energy projects in Norwegian]. Håndbok. Available from: http://www.nve.no/ [Accessed 27th October 2015].

[62] ECON Analyse. Samfunnsøkonomi i fjernvarme og aktørenes incentiver [Social economics in district heating and actors incentives in Norwegian]. Rapport 2003-100. Norway, Oslo, 2003. Available from: https://www.regjeringen.no/globalassets/upload/kilde/oed/rap/2003/0001/ddd/pdfv/195349samfunnsokonomi_i_fjernvarme_og_aktorenes_inecntiver.pdf [Accessed 27th October 2015].

[63] Nohlgren I, Svärd SH, Jansson M, Rodin J. Electricity from new and future plants; 2014. Elforsk report 14:45. 2014, ELFORSK: Stockholm, Sweden. p. 206.

[64] EU, Directive 2004/8/EC of the European Parliament and of the Council - on the Promotion of Cogeneration Based on a Useful Heat Demand in the Internal Energy Market and Amending Directive 92/42/EEC, The European Parliament and the Council, Brussels; 2004.

[65] Chau J, Sowlati T, Sokhansanj S, Preto F, Melin S, Bi X. Techno-economic analysis of wood biomass boilers for the greenhouse industry. Appl Energ 2009;86(3):364-371.

[66] Pantaleo A, Candelise C, Bauen A, Shah N. ESCO business models for biomass heating and CHP: Profitability of ESCO operations in Italy and key factors assessment. Renew Sust Energ Rev 2014;30(0):237-253.

[67] Börjesson M, Ahlgren EO. Biomass gasification in cost-optimized district heating systems A regional modelling analysis. Energ Policy 2010;38(1):168-180.

[68] Truong NL,Gustavsson L. Minimum-cost district heat production systems of different sizes under different environmental and social cost scenarios. Appl Energ 2014;136(0):881-893.

[69] Hedegaard K, Münster M. Influence of individual heat pumps on wind power integration Energy system investments and operation. Energ Convers Manage 2013;75(0):673-684.

[70] Radulovic D, Skok S, Kirincic V. Cogeneration - Investment dilemma. Energy 2012;48(1):177-187.

[71] Danon G, Furtula M, Mandić M. Possibilities of implementation of CHP (combined heat and power) in the wood industry in Serbia. Energy 2012;48(1):169-176.

[72] Obernberger T, Thek G. Cost assessment of selected decentralised CHP application based on biomass combustion and biomass gasification. In: 16th European Biomass Conference and Exhibition, ETA-renewable energies; 2008; Valencia.

[73] Gebremedhin A. Optimal utilisation of heat demand in district heating system - A case study. Renew Sust Energ Rev 2014;30(0):230-236. 
[74] Karlsson Å, Gustavsson L. External costs and taxes in heat supply systems. Energ Policy 2003;31(14):1541-1560.

[75] Yıldırım N, Toksoy M, Gökçen G. District heating system design for a university campus. Energ Buildings 2006; 38(9):1111-1119. 


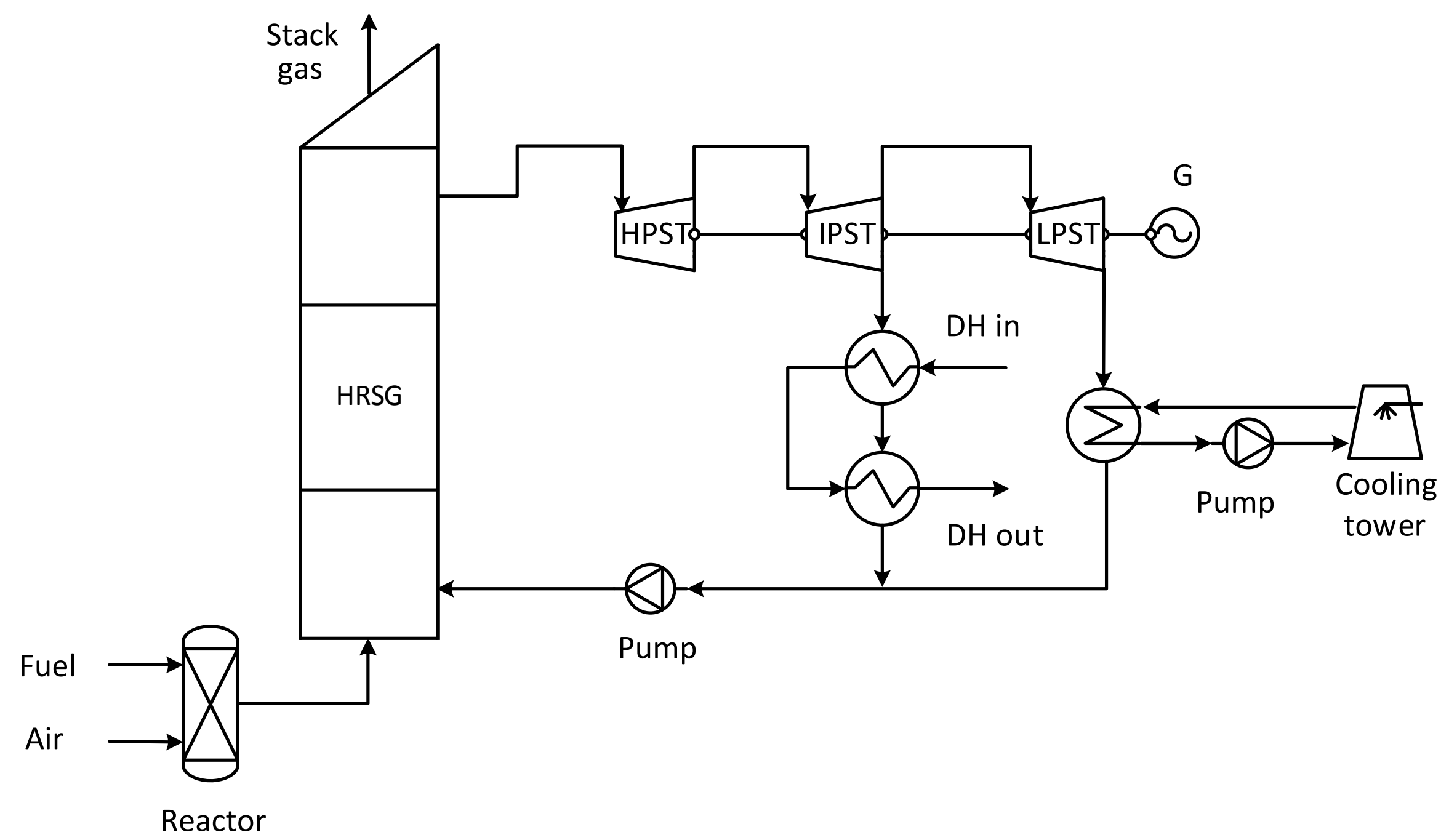


recovery

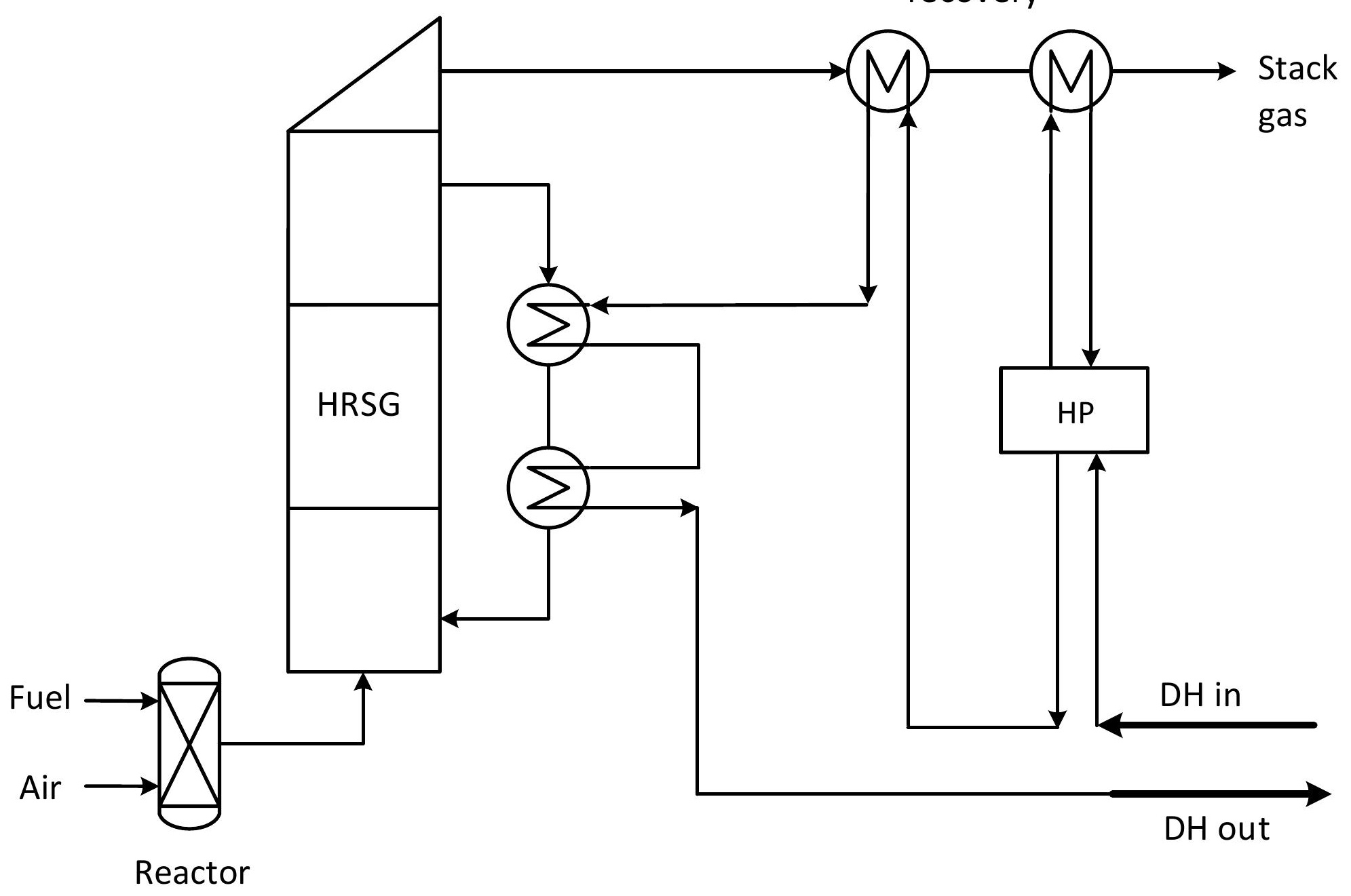




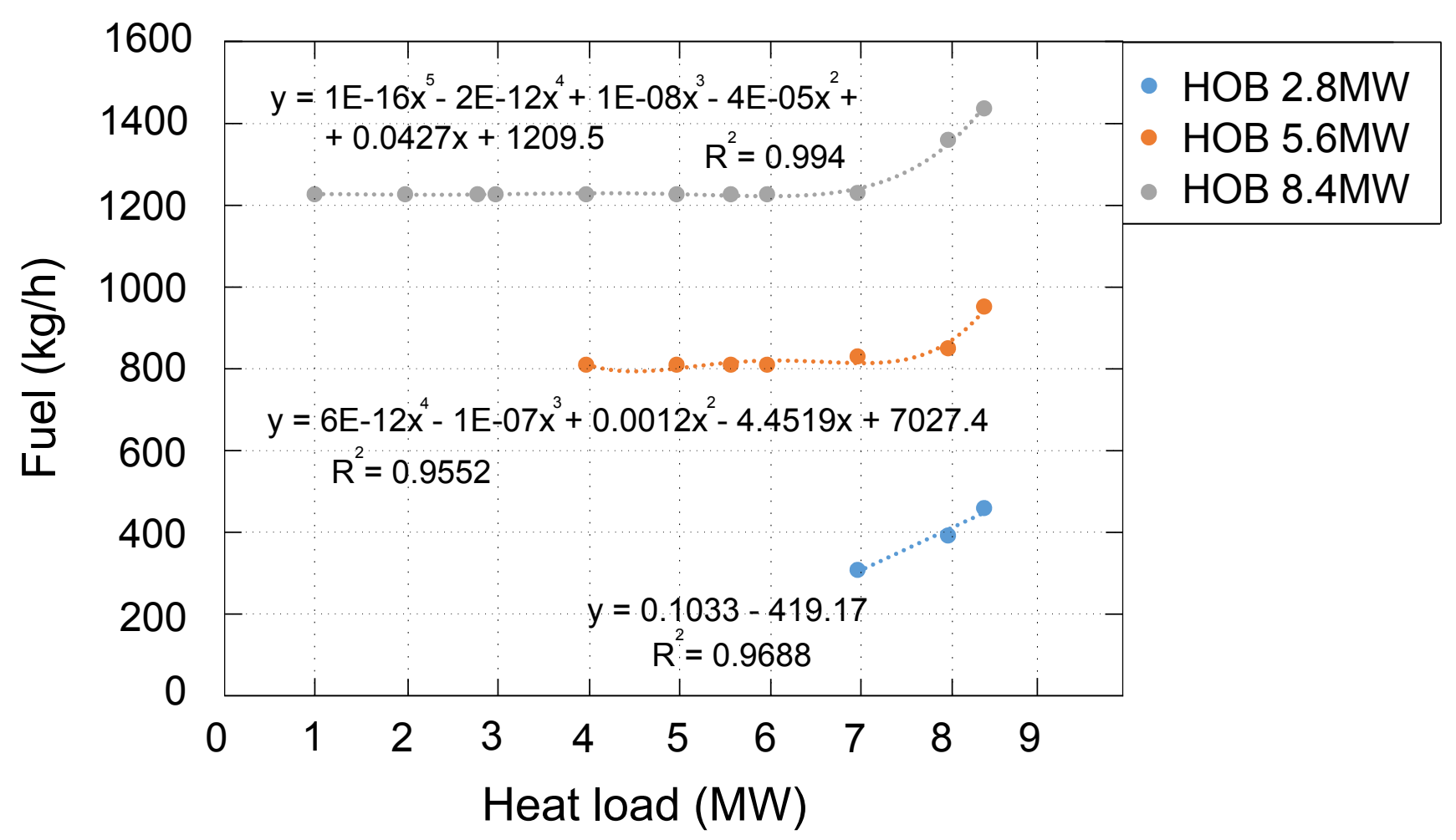


DH out

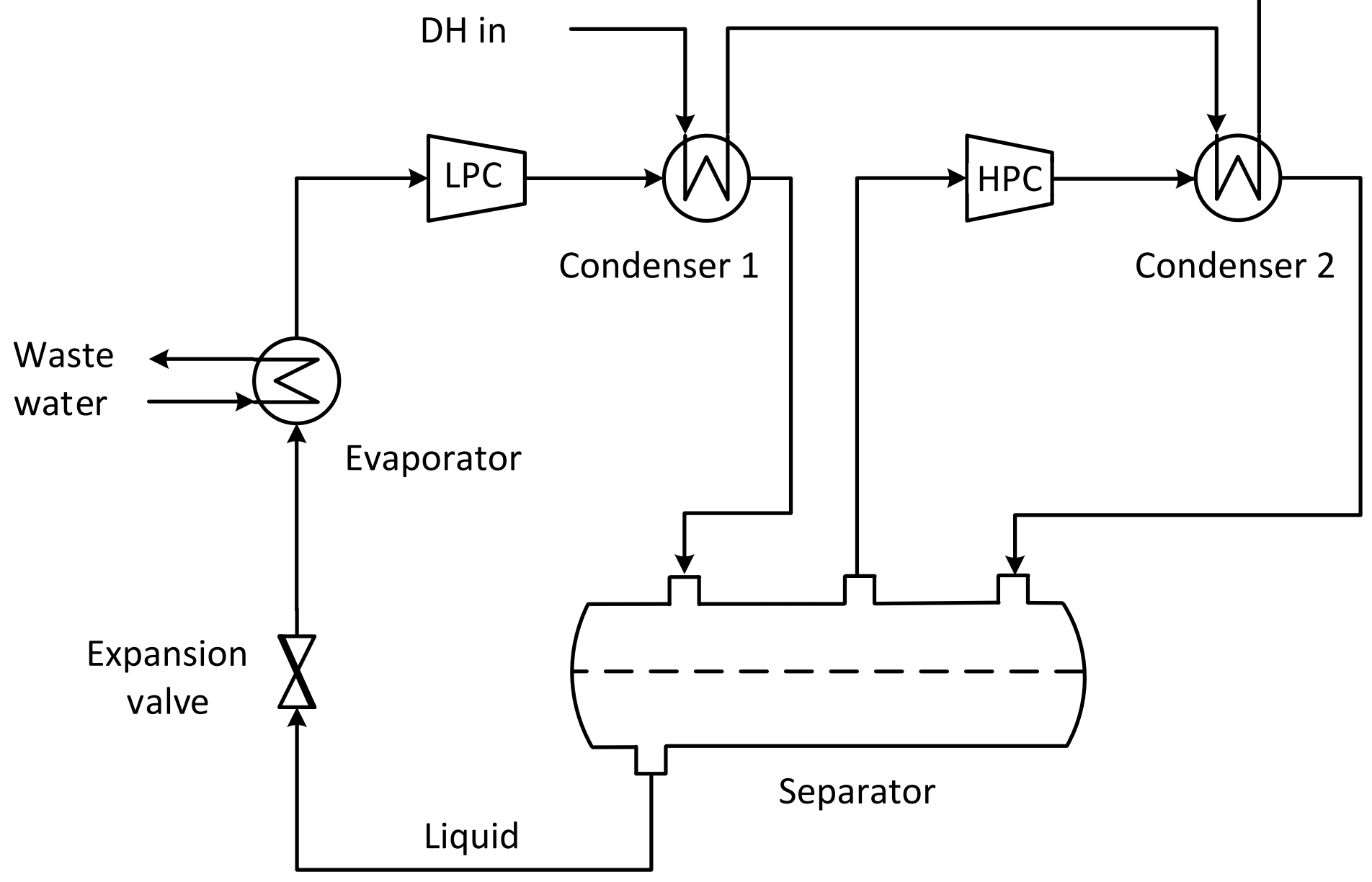




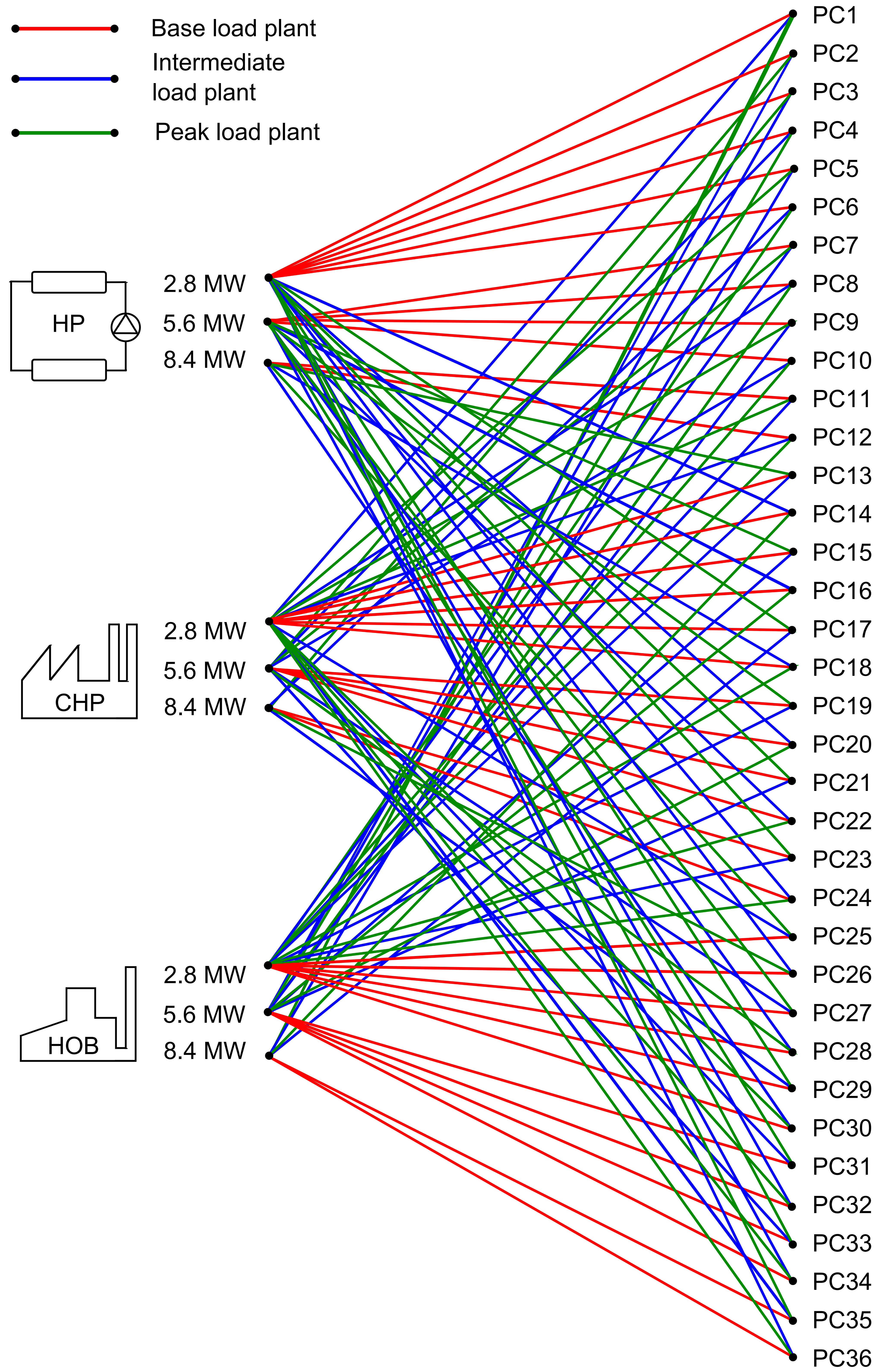


Literature review

\section{Operation data}

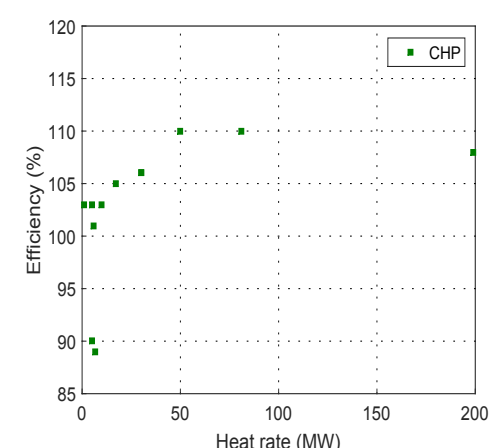

$\mathrm{CHP}$

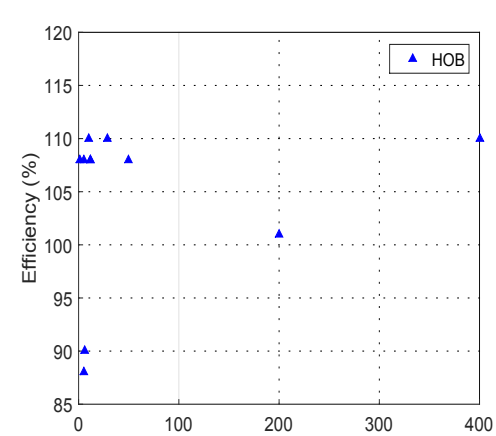

$\mathrm{HOB}$

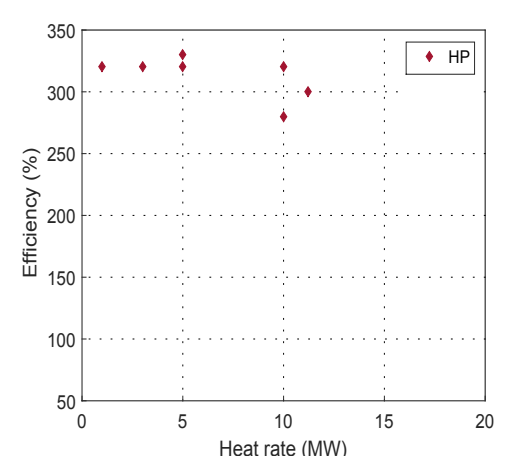

$\mathrm{HP}$

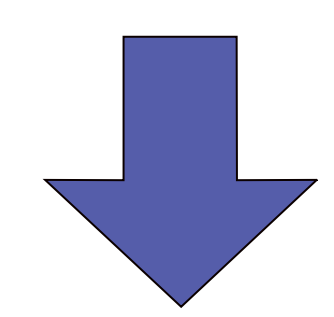

Aspen HYSYS

Plant models
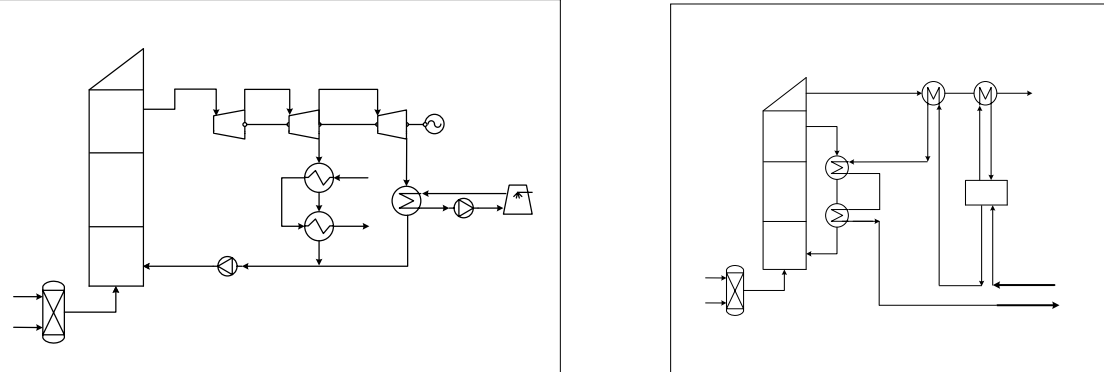

$\mathrm{HOB}$

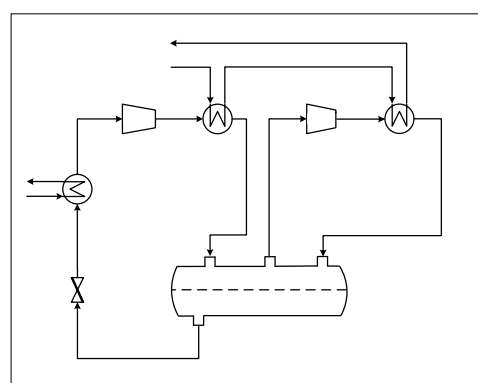

HP
MATLAB
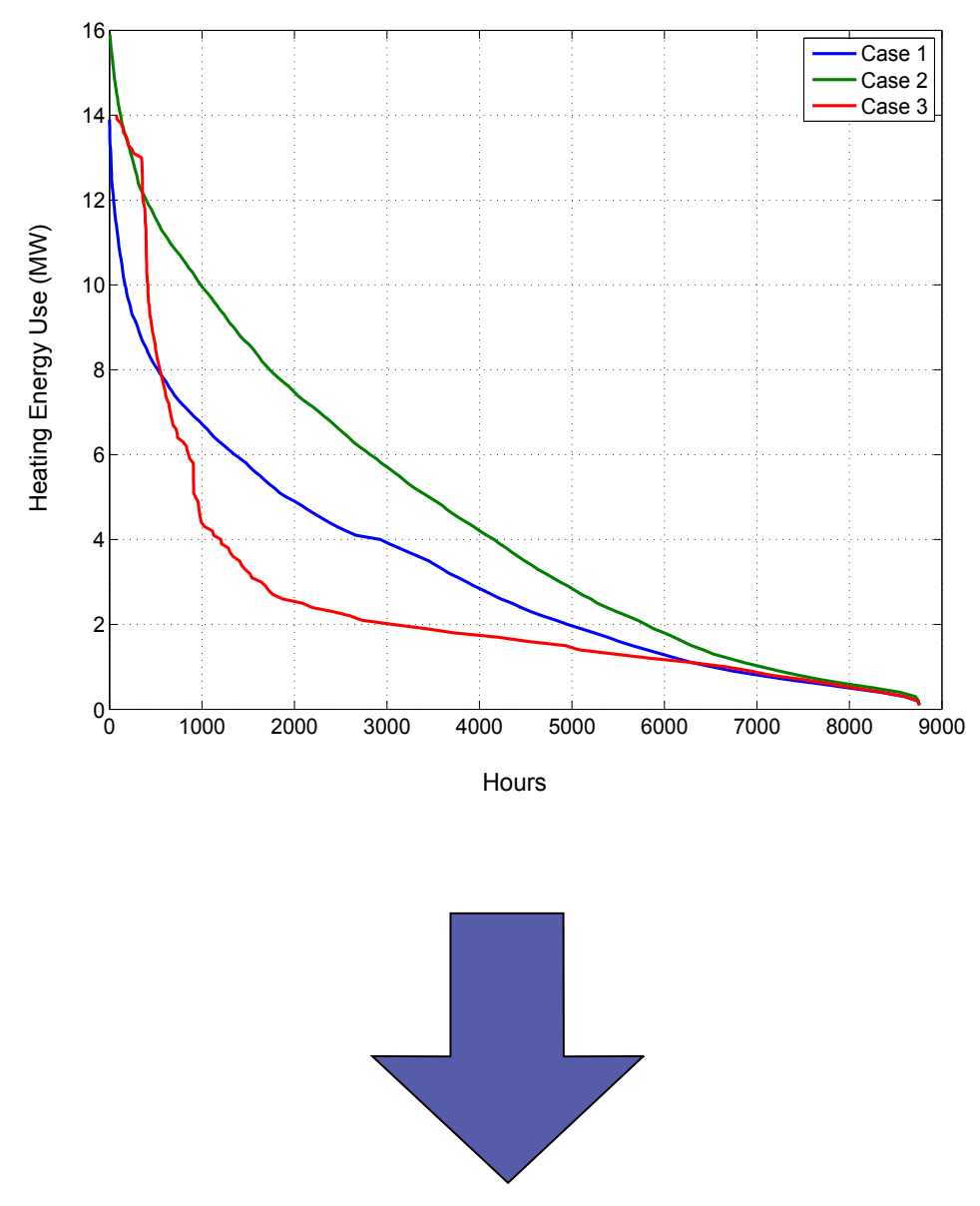

Plant combinations

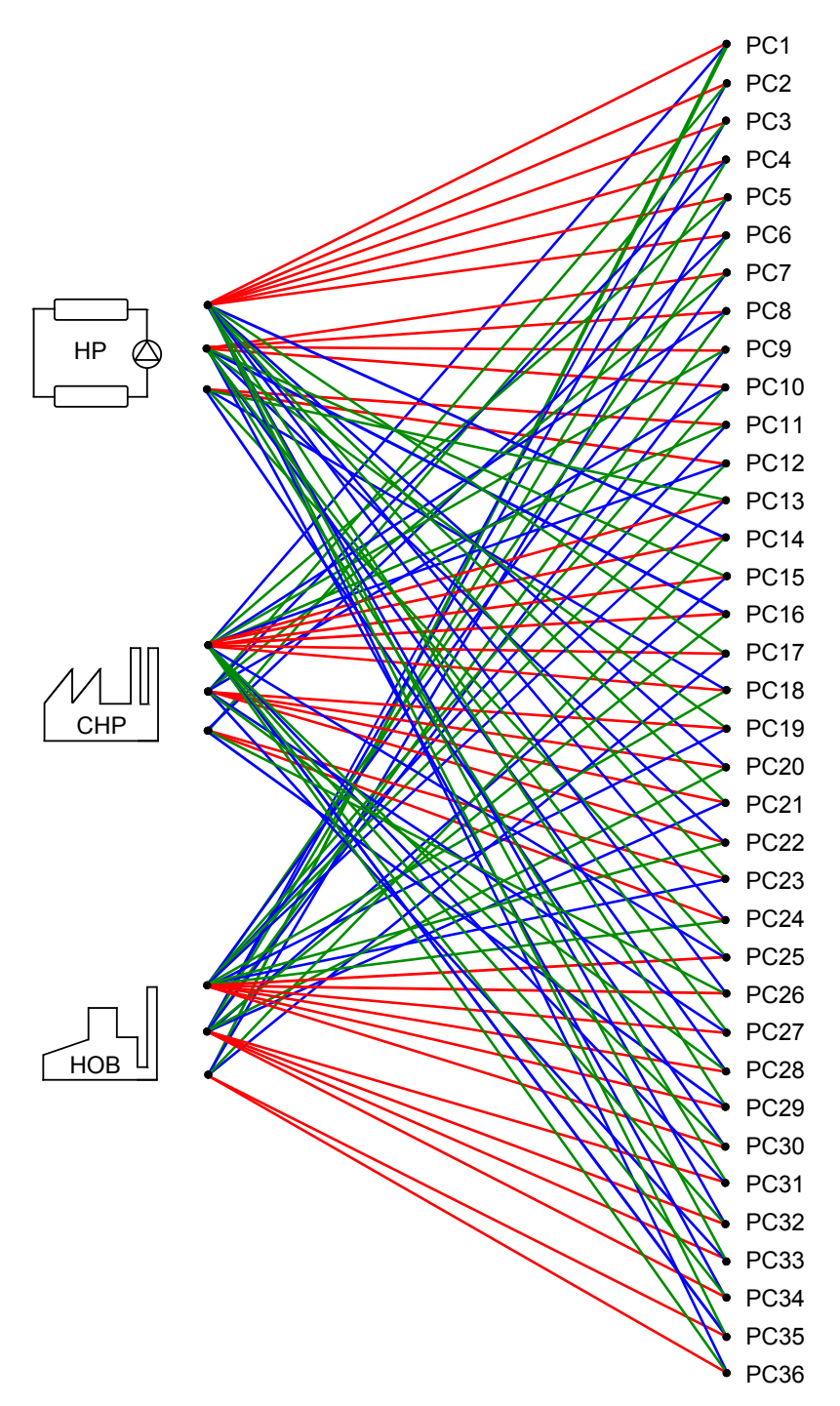




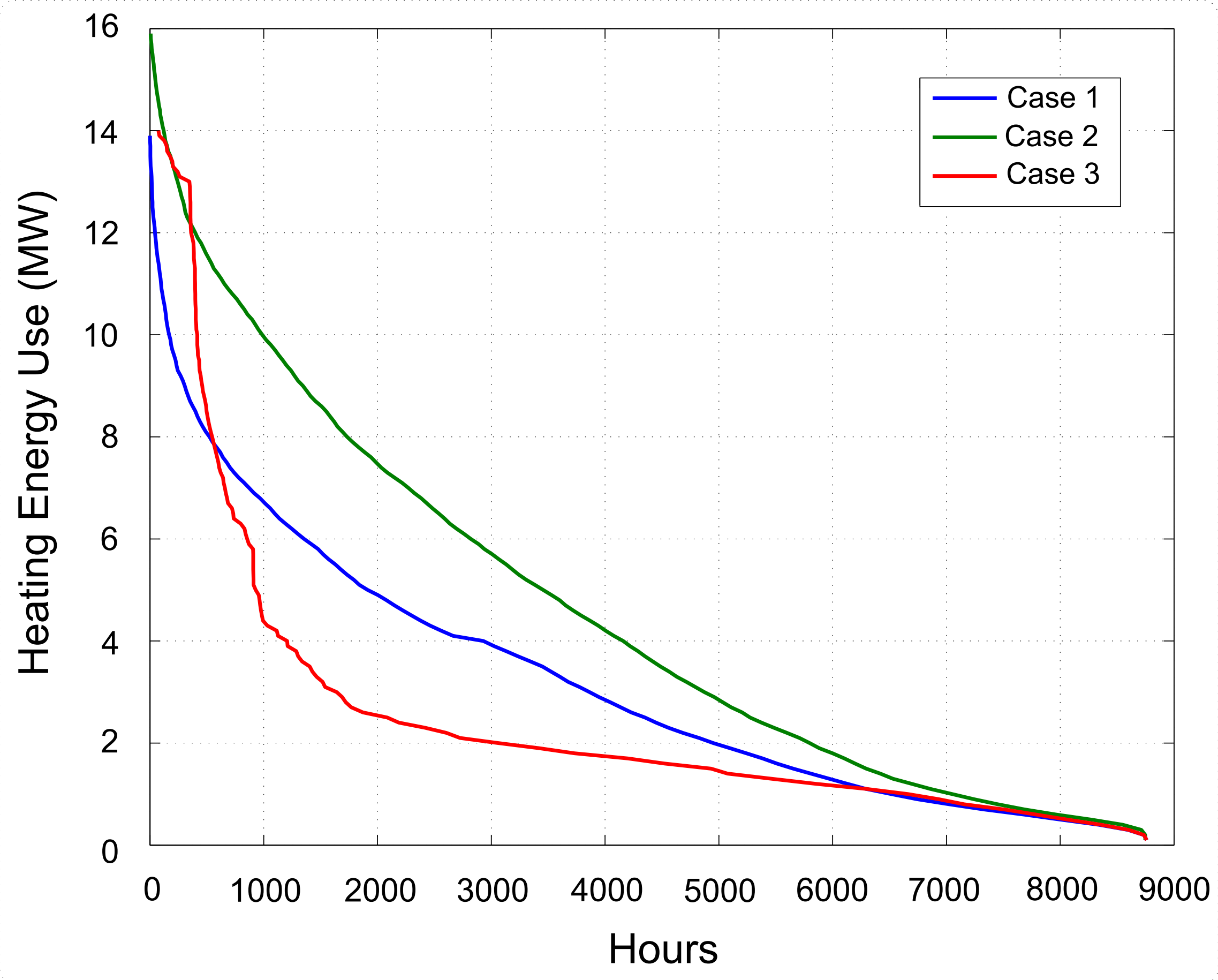






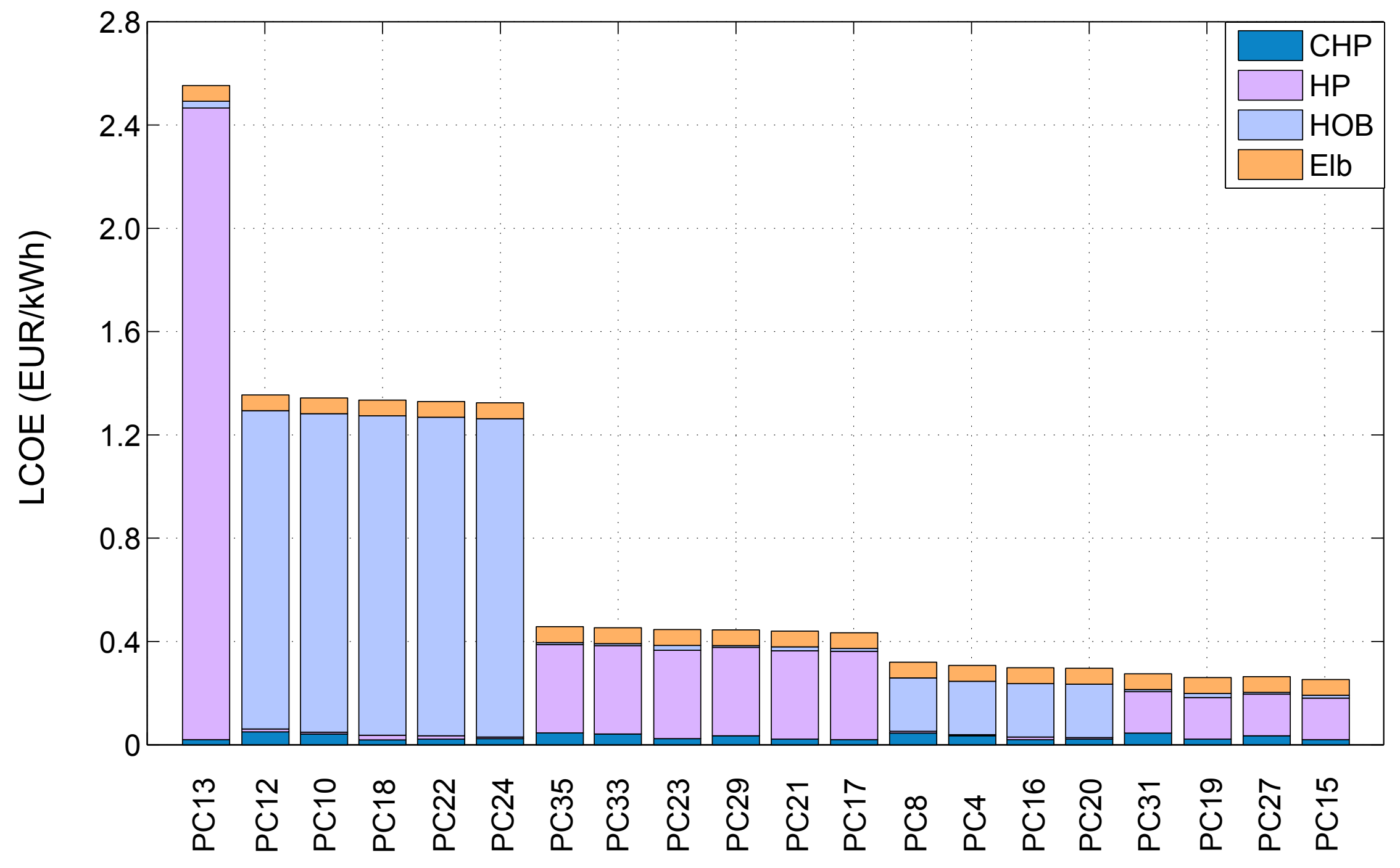




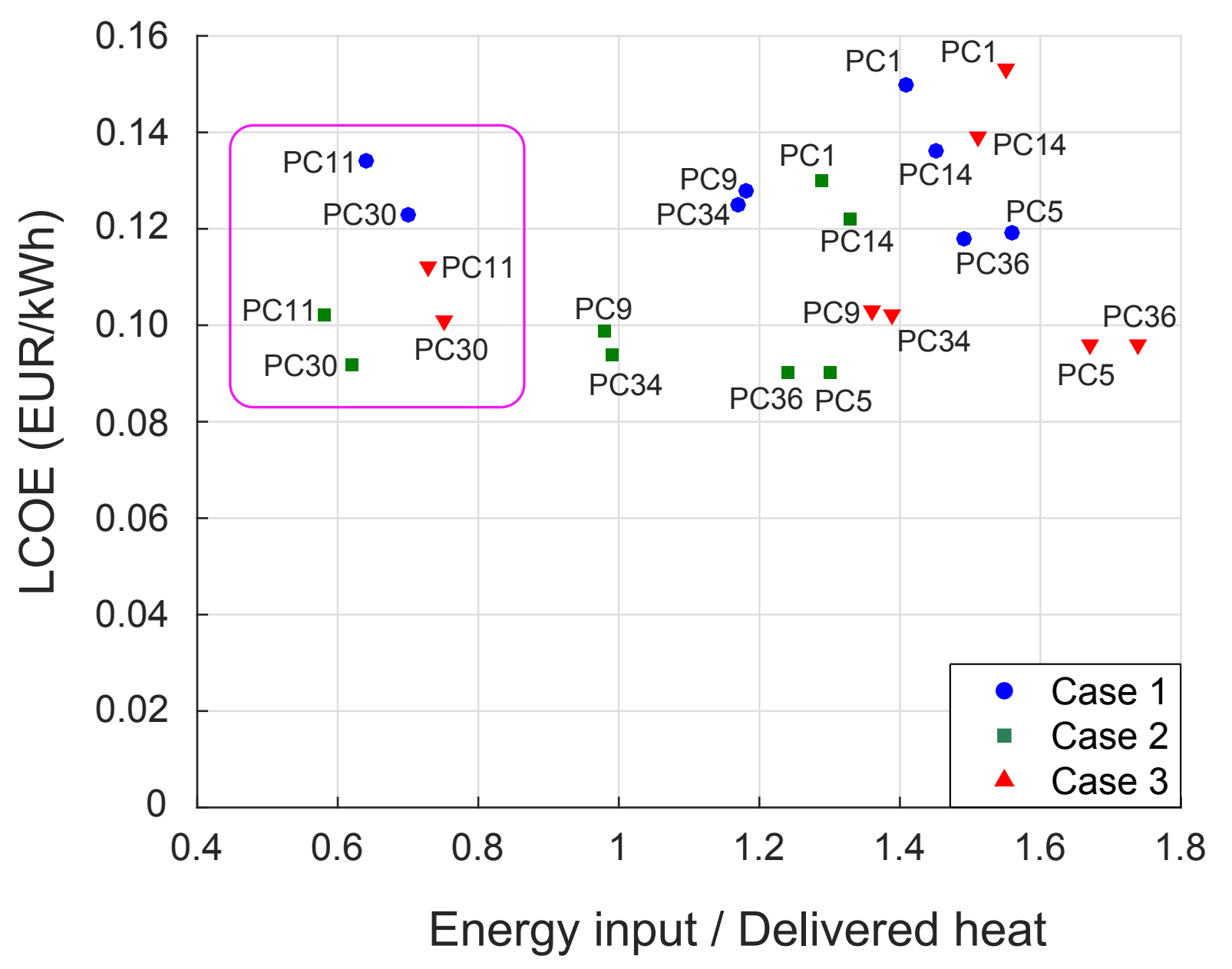

